This is a pre-copy-editing, author-produced PDF of an article accepted for publication in Stock Price Manipulation: Prevalence and Determinants following peer review. The definitive publisher-authenticated version: Review of Finance (2014) 18 (1): 23-66., is available online at: 10.1093/rof/rfs040 


\title{
Stock Price Manipulation: Prevalence and Determinants*
}

\author{
CAROLE COMERTON-FORDE ${ }^{1}$ and TĀLIS J. PUTNIN̦Š ${ }^{2,3}$ \\ ${ }^{1}$ College of Business and Economics, Australian National University, Australia; ${ }^{2}$ UTS \\ Business School, University of Technology Sydney; ${ }^{3}$ Stockholm School of Economics in Riga
}

Forthcoming, Review of Finance

\begin{abstract}
We empirically analyze the prevalence and economic underpinnings of closing price manipulation and its detection. We estimate that approximately one percent of closing prices are manipulated, of which only a small fraction is detected and prosecuted. We find that stocks with high levels of information asymmetry and mid to low levels of liquidity are most likely to be manipulated. A significant proportion of manipulation occurs on month/ quarterend days. Manipulation on these days is more likely in stocks with high levels of institutional ownership. Government regulatory budget has a strong effect on both manipulation and detection.
\end{abstract}

JEL classification: G14

Keywords: market manipulation, prosecution, closing price, high-closing, detection controlled estimation

\footnotetext{
* Corresponding author: Tālis Putniņš, email: talis.putnins@uts.edu.au.

We thank the Australian Stock Exchange, the Australian Research Council and Securities Industry Research Centre of Asia-Pacific for funding (ARC Linkage Project LP0455536). We thank the Securities Industry Research Centre of Asia-Pacific and Thomson Reuters for providing access to data used in this study. Work on this paper was undertaken when Comerton-Forde was employed at the Australian National University. We are grateful for the comments of two anonymous referees, Robert Bartels, Jonathan Batten, Ryan Davies, Jonathan Feinstein, Doug Foster, Thierry Foucault (the editor), Richard Gerlach, Petko Kalev, Si Li, Pamela Moulton, James Rydge, Tom Smith, Terry Walter, Tracy Yue Wang and seminar participants at the 2008 Financial Management Association Annual Meeting, the 2008 European Financial Management Association Annual Conference, the University of Sydney $2^{\text {nd }}$ Annual Microstructure Meeting, the University of Technology Sydney, Macquarie University, the Stockholm School Of Economics in Riga / Baltic International Centre for Economic Policy Studies, and the US Commodity Futures Trading Commission. Previous versions of this paper were circulated under the title "The prevalence and underpinnings of closing price manipulation".
} 


\section{Introduction}

Market manipulation is detrimental to stock markets and their participants. Manipulation harms investor confidence and discourages investor participation in markets. This harms liquidity, increases trading costs and can increase the cost of capital for listed companies. Manipulation distorts prices, thereby reducing market efficiency and causes deadweight economic losses from distorted resource allocation (Pirrong, 1995). Market operators and regulators around the world expend significant resources to ensure they have adequate systems and processes to detect, investigate and prosecute market manipulation (IOSCO, 2000).

Despite its detrimental effects and the costs of regulation, there is only limited empirical research on market manipulation. This is partly due to the fact that manipulation is illegal (Cumming et al., 2011) and only a small fraction of manipulation is detected and prosecuted by market regulators. Thel $(1994$, p. 287$)$ points out "[w]e do not know how often prices are manipulated, how much harm manipulation does or how existing manipulation rules influence behavior". The incentives, means and opportunities to carry out new manipulation schemes are continually evolving (IOSCO, 2000).

This paper focuses on a subset of manipulation - closing price manipulation. We focus on this form of manipulation due to the importance of closing prices. Closing prices are used in a large number of financial contracts and are widely followed by investors. This creates incentives for many different parties to manipulate closing prices by aggressively buying or selling stock at the end of a trading day. For example, mutual fund net asset values

and fund performance are often calculated using closing prices. The performance of a fund determines its ranking relative to competitors and is also commonly used to determine fund manager remuneration. Given these incentives it comes as little surprise that some fund 
managers manipulate closing prices. ${ }^{1}$ Closing prices have also been manipulated to profit from positions in stock derivatives ${ }^{2}$ and by brokers attempting to improve the appearance of their execution ability. ${ }^{3}$ Closing prices have been manipulated during pricing periods for seasoned equity issues and takeovers, to maintain listing on an exchange with minimum price requirements, to avoid margin calls, and on stock index rebalancing days to gain inclusion in an index.

Manipulation of closing prices makes them a less accurate measure of a stock's value, and therefore creates negative externalities for agents using these prices for benchmarking, contracting and trading purposes (Ben-David et al., 2011). By reducing the frequency of manipulation and the associated negative externalities, regulation can increase aggregate welfare. These benefits need to be balanced against the costs of regulation and therefore the socially optimal level of enforcement is a function of the frequency of manipulation, among other factors (DeMarzo et al., 1998).

Although market participants perceive closing price manipulation to be common, we are not aware of any attempts to estimate the prevalence of manipulation or its detection. ${ }^{4}$ If

\footnotetext{
${ }^{1}$ This type of manipulation is commonly conducted on the last day of a reporting period such as a monthend or quarter-end. See Carhart et al. (2002), Bernhardt and Davies (2005). This practice is also known as 'marking the close', 'painting the tape', 'high closing', 'marking up' or 'portfolio pumping'. Another reason for manipulation by fund managers is to influence the net asset value at which money enters and exits the fund.

${ }^{2}$ See, for example, Kumar and Seppi (1992) and Ni et al. (2005).

${ }^{3}$ See, for example, Hillion and Suominen (2004).

${ }^{4}$ For example, an article in news magazine Maclean's (July 10, 2000, Vol. 113 No. 28, page 39) comments "nearly everyone seems to agree that high closing is common". An article in Financial News ("Mutual funds come under fire", September 21, 2003) states "in the US the prevalence of the closing price manipulation has yet to be established, although Spitzer [Eliot Spitzer, New York state Attorney-General] claims that incriminating evidence is pouring in at an unexpectedly high rate."
} 
investors perceive the frequency of manipulation to be higher than the actual level then they will be unnecessarily discouraged from participating in the market. ${ }^{5}$ Similarly, although we know some of the reasons why closing prices are manipulated, the relative importance of the various reasons and the nature of stocks most likely to be affected by manipulation are not well understood. A better understanding of these issues would not only help regulators to be more effective at detecting and deterring manipulation, but also allow a better assessment of the social costs of closing price manipulation and the types of stocks that are most likely to be affected by the negative externalities. Understanding when and in which stocks manipulation is most likely to occur also has implications for financial contract design, which involves balancing the costs of more complexity against the benefits of increased robustness to manipulation attempts (e.g., moving from closing prices to volume-weighted average prices, "manipulation-proof" performance measures (Goetzmann et al., 2007), and using call auctions to determine closing prices (Hillion and Suominen, 2004)).

This paper is the first to analyze empirically the factors that drive closing price manipulation and its detection, and estimate its prevalence in stock markets. We hand collect a sample of actual manipulation cases and use detection controlled estimation methods that explicitly take into consideration that only a non-random subset of manipulation is detected and prosecuted. Our sample of prosecuted manipulation cases is from four US and Canadian stock exchanges: the New York Stock Exchange (NYSE), the American Stock Exchange (AMEX), the Toronto Stock Exchange (TSX) and the TSX Venture Exchange (TSX-V). We do not seek to resolve the debate about what constitutes market manipulation (e.g., Fischel and Ross, 1991; Kyle and Viswanathan, 2008). For the purpose of our analysis we simply adopt the US and Canadian regulators' definition.

\footnotetext{
${ }^{5}$ Following the 1987 stock market crash the NYSE established a panel of experts to review market volatility and investor confidence. The panel highlighted the importance of enhancing regulatory capacity to detect and punish manipulative activities, but also commented on the need for the market to "hear the facts" about the extent of manipulative and abusive activities.
} 
We estimate that for each prosecuted instance of closing price manipulation approximately 308 to 326 instances of manipulation remain undetected or not prosecuted and that this rate differs substantially across exchanges. We find that stocks with high levels of information asymmetry and mid to low levels of liquidity are most likely to be manipulated. A significant proportion of manipulation occurs on month-end and quarter-end days. In addition, a high proportion of mutual fund ownership increases the likelihood that a stock is manipulated at month/quarter end. We also find that manipulators dislike idiosyncratic volatility, possibly because it increases the risk of both the manipulation being unsuccessful and the stock drawing the attention of regulators. We also find that larger government regulatory budgets increase the rate of prosecution and deter manipulation.

Our estimates of the fraction of manipulation that remains undetected are useful in evaluating the effectiveness of regulation. The insights into what drives manipulation have implications for improving regulatory efficiency by focusing regulatory effort where manipulation is most likely. This study provides an instrument to calculate the probability of manipulation that has not been detected or prosecuted. It can be used to study undetected manipulation and refine alerting parameters of market surveillance systems.

This paper is related to the small number of empirical studies of market manipulation cases, such as corners (Allen et al., 2006), squeezes (Merrick et al., 2005; Jegadeesh, 1993; Jordan and Jordan, 1996), the stock pools of the 1920s (Mahoney, 1999; Jiang et al., 2005) and 'pump-and-dump' manipulation (Aggarwal and $\mathrm{Wu}, 2006$ ). Each of these forms of market manipulation is quite different in nature from closing price manipulation and therefore our paper complements this literature, rather than overlaps it. The only other empirical study to examine a systematic sample of closing price manipulation cases is Comerton-Forde and Putniņš (2011a). In contrast to the present study which analyses the determinants and frequency of closing price manipulation, Comerton-Forde and Putniņš (2011a) examine the effects of closing price manipulation. They find that manipulation is associated with large increases in day-end returns, return reversals, trading activity and bid-ask spreads. A further 
difference from existing studies is our use of econometric techniques that overcome the biases caused by incomplete detection. This is particularly important given the small fraction of closing price manipulation that is prosecuted.

The paper proceeds as follows. The next section defines the empirical model. Sections 3 and 4 describe the variables and data. In Section 5 we present results, discuss implications and conduct a number of robustness tests. The paper's final section offers some conclusions.

\section{Empirical Model of Manipulation and Detection}

\subsection{THE ECONOMETRIC PROBLEMS CAUSED BY INCOMPLETE DETECTION}

Analyzing prosecuted violations without accounting for the non-random detection and prosecution processes can lead to substantial biases in inference about the characteristics or frequency of violations. This problem is overlooked or inadequately addressed in much of the empirical literature. For example, Aggarwal and Wu (2006) analyze a sample of 'pumpand-dump' manipulation cases prosecuted by the SEC. If cases of manipulation that cause large price changes are more likely to be detected and prosecuted by the SEC, then the inferences of Aggarwal and $\mathrm{Wu}$ about the effect of manipulation on prices, or what types of stocks are more likely to be manipulated, are potentially significantly biased. The difficulty in estimating the underlying rate of violations (consisting of detected and undetected violations) is more obvious - if undetected violations cannot be observed, how can we infer what fraction goes undetected?

The econometric problems caused by incomplete detection are well documented by Feinstein $(1990,1991)$. To overcome these problems, Feinstein (1990) develops detection controlled estimation (DCE) methods that allow inference about undetected violations, which are not directly observable. The idea behind DCE is simple: jointly estimating models of the detection and violation processes explicitly allows for incomplete detection. In its simplest 
form, a DCE model is a system of two simultaneously estimated equations: one modeling violation and the other modeling detection conditional on violation having occurred. ${ }^{6}$

\subsection{NUMERICAL EXAMPLE OF INCOMPLETE DETECTION AND MODEL IDENTIFICATION}

The intuition of how jointly estimating the detection and violation processes allows unbiased inference about unobservable characteristics and frequencies is not straight forward. We therefore provide a simple numerical example of incomplete detection to illustrate the intuition of how identification works in our econometric model.

Suppose that as illustrated in Table I Panel A in a population of 100 people 50 have high IQ and 50 have low IQ, and in each group 10 of the 50 people are manipulators. The true frequency of manipulators in the population is $20 / 100=20 \%$ and IQ has no effect on the likelihood of being a manipulator because $\operatorname{Pr}($ Manipulator $\mid$ High IQ) $=\operatorname{Pr}($ Manipulator $\mid$ Low IQ) $=10 / 50=20 \%$. Suppose also that manipulators differ in some systematic way, for example, they have lower risk aversion than non-manipulators.

Now suppose 9 out of the 10 low-IQ manipulators are caught and prosecuted, but only 1 out of the 10 high-IQ manipulators is caught and prosecuted (as illustrated in Table I Panel B) because the high-IQ manipulators are better at avoiding detection or concealing incriminating evidence that is required for successful prosecution. If we were to ignore incomplete detection and simply use the observed prosecution cases to study the effects of IQ on the likelihood of being a manipulator we would conclude that $\operatorname{Pr}($ Manipulator $\mid$ High IQ) $=$

\footnotetext{
${ }^{6}$ The DCE model is similar to Heckman-style selection bias correcting models in that both explicitly model the process that causes the sample to be a non-random subset of the population. However, Heckman-style models are not suited to incomplete detection problems. The reason is that one of the outcomes of the selection process, undetected or not prosecuted manipulation, cannot be directly observed as it would be in a Heckman-style application (non-respondents in survey data, for example).
} 
$1 / 50=2 \%$ and $\operatorname{Pr}($ Manipulator $\mid$ Low IQ $)=9 / 50=18 \%$ and therefore that having low IQ makes a person significantly more likely $(18 \%-2 \%=16$ percentage points) to be a manipulator. We would estimate the frequency of manipulators in the population as $(9+1) / 100=10 \%$; half that of the true manipulator frequency of $20 \%$. This illustrates the bias in inference about the characteristics and frequency of manipulation when there is a failure to explicitly account for incomplete detection.

How could we avoid or at least reduce the biases? Suppose we know that IQ affects the probability that a manipulator is detected/prosecuted (but it does not affect the likelihood of being a manipulator), and the level of risk aversion affects the likelihood of being a manipulator (but it does not affect the probability that a manipulator is detected/prosecuted), although we do not know the direction or magnitude of either effect. In the first step we could use the subsample in which detection rates appear to be higher (the low-IQ individuals, because there we have $9 / 50$ prosecutions compared to $1 / 50$ in the high-IQ group) to estimate how risk aversion (RA) affects the probability of being a manipulator. Recall that there are 10 manipulators in the low-IQ population (and manipulators have low RA) but only 9 are prosecuted, so we observe 9 manipulators and 10 low-RA individuals and therefore we estimate $\operatorname{Pr}($ Manipulator $\mid$ Low RA $)=9 / 10=90 \%$. In the second step we could estimate the number of high-IQ manipulators by using the inferred relation between RA and the likelihood of being a manipulator and the observation that 10 individuals in the high-IQ population have low RA, giving the estimate $10 \times 90 \%=9$ manipulators. Recall that incomplete detection was more pronounced in the high-IQ subsample and notice that we used the relation between RA and manipulative tendencies inferred from the subsample in which detection is more reliable to improve our estimate of the prevalence of manipulators in the high-IQ subsample. The improved estimates are consistent with the example's underlying assumption that IQ has no effect on the likelihood of being a manipulator because $\operatorname{Pr}($ Manipulator $\mid$ High IQ) $=$ $\operatorname{Pr}($ Manipulator $\mid$ Low IQ $)=9 / 50=18 \%$, i.e., we have corrected the bias that existed previously. The improved estimate of the frequency of manipulators in the population is 
$(9+9) / 100=18 \%$, which is substantially closer to the true frequency of $20 \%$ than the previous estimate of $10 \%$.

This example is kept deliberately simple for the sake of illustration; therefore it is important to note a few points on how it relates to our detection controlled econometric model for manipulation. In the example, the observations with a high detection rate are used to infer the characteristics of manipulators, which in turn are used to identify likely undetected manipulators. However, in reality identification also works simultaneously in the other direction, i.e., observations with a high probability of manipulation are used to infer the characteristics of detection, which in turn are used to improve estimates of the characteristics of manipulators, and so forth. In the econometric model inference about unobservable characteristics occurs in a simultaneous rather than a two-step procedure. This also means that the model is able to produce unbiased estimates of the unobservable population parameters, whereas the example simply 'improved' on the naïve estimates by iterating through the described inference process once. Similar to the example, the model requires that at least one variable predicts manipulation but not detection, or the other way round, but one does not need to know ex-ante the sign or magnitude of the relation. The predictors of manipulation and detection need not be uncorrelated as was the case in the example, they can contain noise, and some variables can predict both manipulation and detection.

Finally, inference is not limited to just the types of manipulation detected by regulators, as long as the different types of manipulation share some common characteristics. For example, suppose some fund managers and some options traders are manipulators, but regulators only detect and prosecute fund managers. Fund managers would be overrepresented in the prosecution sample compared to options traders, allowing the model to infer that detection/prosecution rates are higher for fund managers. The model would infer the general characteristics of manipulators (such as low risk aversion in the previous example) from the prosecuted fund managers and use those characteristics to identify the manipulating options traders that have not been prosecuted. 


\subsection{THE MODIFIED DETECTION CONTROLLED ESTIMATION MODEL}

We modify the basic DCE model from Feinstein (1990) by separating the detection process into two stages. Therefore, our model consists of three stages: manipulation, direct detection and indirect detection.

The reason for modeling detection as a two-stage process is as follows. Exchanges and regulators operate real-time computer surveillance systems that generate alerts in response to 'unusual' or potentially manipulative behavior. Different surveillance departments use different systems and set varied criteria and thresholds for determining unusual behavior. However, all alerting systems use price and volume variables to identify instances of unusual behavior. We refer to detection by automated surveillance systems as direct detection. Once a trader has been detected for manipulating prices, further investigation of their trading records can reveal other instances of manipulation, attempted manipulation or conspiring manipulators that were not detected by automated surveillance system alerts. Also, some instances of manipulation that do not trigger alerts in surveillance systems are brought to the attention of the regulator by complaints from market participants. We refer to detection of manipulation that does not trigger alerts in surveillance systems as indirect detection.

The manipulation sample contains examples of indirect detection: instances in which day-end returns are zero or even negative despite the manipulator's intent to inflate the closing price. These instances represent unsuccessful attempts at manipulation or cases in which the manipulator reduced a day-end price decrease, for example, by keeping prices flat when they would have fallen without the manipulative buying. We model direct and indirect detection separately because their empirical characteristics are different. For example, directly detected manipulation is likely to have a large abnormal return on the day of manipulation whereas indirectly detected manipulation will not. 
Prosecution is implicit in our model of detection. Although the two processes could be modeled separately, such a model is likely to suffer from identification problems due to the lack of observable variables that affect detection but not prosecution or vice versa. Such variables include, for example, whether incriminating telephone conversations are recorded or whether incentives and gain to the manipulator can be convincingly demonstrated in court. Therefore, we model detection and prosecution as a single process and simply refer to this as detection, consistent with other DCE models in the literature.

The propensity for closing price $i$ (the closing price of a particular stock on a particular day) to be manipulated is modeled as a continuous latent variable, $Y_{1 i}^{*}$, that is a function of market-, stock- and time-specific attributes, $X_{1 i}$.

$$
\begin{aligned}
& Y_{1 i}^{*}=X_{1 i} \beta_{1}+\varepsilon_{1 i} \\
& Y_{1 i}=\left\{\begin{array}{llll}
1 & \text { (manipulated) } & \text { if } & Y_{1 i}^{*}>0 \\
0 & \text { (not) } & Y_{1 i}^{*} \leq 0
\end{array}\right\}
\end{aligned}
$$

$Y_{1 i}$ is the binary variable for whether closing price $i$ has been manipulated. $Y_{1 i}$ cannot be directly observed if detection is incomplete. Instead, we observe closing prices that have been manipulated and detected.

Conditional on manipulation having occurred, the propensity for manipulation of closing price $i$ to be directly detected by a regulator is modeled as a continuous latent variable, $Y_{2 i}^{*}$, that is a function of market-, stock- and time-specific attributes, $X_{2 i}$.

$$
\begin{gathered}
Y_{2 i}^{*}=X_{2 i} \beta_{2}+\varepsilon_{2 i} \\
Y_{2 i}=\left\{\begin{array}{lll}
1 & \text { (directly detected) } \\
0 & \text { (not) } & \text { if } \begin{array}{l}
Y_{2 i}^{*}>0 \\
Y_{2 i}^{*} \leq 0
\end{array}
\end{array}\right\}
\end{gathered}
$$

Similarly, $Y_{2 i}$ is the binary variable for whether manipulated closing price $i$ is directly detected. 
Conditional on manipulation having occurred and not being directly detected, the propensity for manipulation of closing price $i$ to be indirectly detected is modeled as a continuous latent variable, $Y_{3 i}^{*}$, that is a function of market-, stock- and time-specific attributes, $X_{3 i}$.

$$
\begin{aligned}
& Y_{3 i}^{*}=X_{3 i} \beta_{3}+\varepsilon_{3 i} \\
& Y_{3 i}=\left\{\begin{array}{lll}
1 & \text { (indirectly detected) } & \text { if } \\
0 & \text { (not) } & \begin{array}{l}
Y_{3 i}^{*}>0 \\
Y_{3 i}^{*} \leq 0
\end{array}
\end{array}\right\}
\end{aligned}
$$

$Y_{3 i}$ is the binary variable for whether the manipulated closing price $i$ is indirectly detected.

$<$ Figure 1 here $>$

Figure 1 graphically illustrates our three-equation DCE model. A sample of closing prices falls into two disjoint sets, $\mathrm{A}$ and $\mathrm{A}^{\mathrm{c}}$. Set $\mathrm{A}$ consists of closing prices that have been manipulated and either directly or indirectly detected. Set $A^{c}$ consists of closing prices that have either not been manipulated or have been manipulated but have evaded both direct and indirect detection. $Y_{1 i}, Y_{2 i}$ and $Y_{3 i}$ cannot be separately observed. We observe sets $\mathrm{A}$ and $\mathrm{A}^{\mathrm{c}}$ in a sample of data and estimate the model's parameters using maximum likelihood, as in Poirier (1980) and Feinstein (1990). The details and derivation of the likelihood function are in Appendix A.

\subsection{ALTERNATIVE MODELS}

Identification in DCE models is achieved through predictor variables that are uniquely associated with one stage. That is, variables that predict manipulation but not direct or indirect detection, variables that predict direct detection but not manipulation or indirect 
detection and variables that predict indirect detection but not manipulation or direct detection. $^{7}$ In order to find such variables we exploit the helpful fact that detection occurs after manipulation. Variables that are only observed after manipulation can affect the ex-post probability of detection but not the ex-ante incentives to engage in manipulation and therefore provide a natural set of variables for identification (a similar approach is used by Wang (2012)). Distinguishing between direct and indirect detection is more difficult because we do not have a clear temporal order to exploit. Therefore, we estimate an alternative twoequation model (similar to the original DCE model used in Feinstein $(1989,1990)$ ) that allows detection to result from direct or indirect detection but makes no effort to distinguish between the two. Appendix B contains the equations and likelihood function for this model.

Our DCE model, like the rest of the DCE literature, assumes errors are independently distributed. In practice, the errors of one process (e.g., manipulation) may be correlated with the errors of another (e.g., detection), if expectations simultaneity exists and is not incorporated into the model. For example, regulators may be more likely to investigate stock-days that have a higher probability of manipulation. We therefore estimate a third model with expectations simultaneity in which we add the probability of manipulation, $M\left(X_{1 i} \beta_{1}\right)$, to the right hand side of both detection equations. This model allows the probability of a regulatory investigation to depend on the probability of manipulation. Appendix B contains the full set of equations and likelihood function.

\section{Variables and Model Specifications}

Table II defines the independent variables used in our econometric models. Most variables primarily influence either manipulation or detection, but have indirect effects on the other process due to interaction between manipulators and regulators. For example, if fund managers manipulate closing prices at quarter-ends then a primary determinant of the

\footnotetext{
${ }^{7}$ For a more formal discussion of the identification issue see Feinstein (1990).
} 
probability of manipulation is whether or not a day is a quarter-end. A regulator that is aware of this association is more likely to investigate suspicious trading on quarter-end days and therefore whether or not a day is a quarter-end is a secondary determinant of the probability of detecting manipulation. We discuss variables according to their primary association - first those associated with manipulation, then detection and lastly both manipulation and detection.

\section{$<$ Table II here $>$}

An order can move prices for at least two reasons: (i) it mechanically moves price from the bid quote to the ask quote (or vice versa) or beyond the prevailing best quotes by executing the volume at the best quotes; and (ii) it conveys information and causes revision of beliefs about the value of the stock. A manipulator can exploit one or both of these mechanisms to influence prices. The ability to use the first mechanism to manipulate a stock price depends on the liquidity of the stock, which we measure using market capitalization, turnover, the Amihud (2002) illiquidity metric (ILLIQ), and bid-ask spread, although at no stage are all four variables included in a model at the same time. The ability to use the second mechanism to manipulate a stock price depends on the degree of information asymmetry, which we measure using the number of analysts' forecasts of the stock's earnings (analyst coverage) and a dummy variable for whether or not the stock is included in a broad market index. Some closing price manipulation is conducted by company insiders. In addition to analyst coverage, monitoring by institutional investors may constrain insider manipulation. We proxy for institutional holdings with the percentage of shares held by mutual funds.

We also include variables that capture various motivations for manipulation. Theoretical and empirical evidence suggests that stock prices are manipulated to profit from options on the underlying stock or from futures contracts on indices, particularly in the period immediately prior to expiry (e.g., Stoll and Whaley, 1991; Kumar and Seppi, 1992; Jarrow, 
1994; and Ni et al., 2005). Therefore, we include a dummy variable for whether or not a stock has listed options and a second dummy variable indicating, for stocks with listed options, whether it is the last trading day prior to expiry of the options. Fund managers are known to manipulate closing prices at the end of reporting periods such as the last day of a month or a quarter (e.g., Carhart et al., 2002; Bernhardt and Davies, 2009; and Ben-David et al., 2011). Therefore, we include dummy variables for the last trading day in each month and quarter, and interactions of the dummy variables with the percentage of shares held by mutual funds. Closing prices are also known to have been manipulated to avoid margin calls and to maintain a stock's listing on an exchange with a minimum price requirement. These incentives for manipulation are triggered when a stock's price falls to a critical level and therefore are more likely to occur following declines in a stock's price. We include a price trend variable (a stock's rolling one-month return) to examine these two and other similar motivations related to price movements. Finally, to investigate manipulation associated with secondary equity offerings (SEO), we include a dummy variable for one-month periods prior to each SEO issue. The one-month window is likely to contain the SEO pricing periods, which is when closing prices might be manipulated.

Volatility is likely to have more than one effect on manipulation. Hillion and Suominen (2004) suggest that broker execution ability is more valuable when volatility is higher and therefore high volatility leads to closing price manipulation by brokers that attempt to alter their customers' inference about their execution ability. However, volatility can also deter manipulators if, for example, manipulators perceive volatile stocks as more likely to attract the regulator's attention. This could occur due to an extreme day-end abnormal return or due to an overnight return that creates a return reversal. Further, idiosyncratic volatility presents a risk to a manipulator because the stock price can move against them. Our sample of prosecuted instances of manipulation contains cases in which, despite the manipulator's intent to increase the price, the day-end return is negative. We 
measure idiosyncratic volatility using the standard deviation of residuals from a market model of returns.

The variables associated primarily with detection and prosecution include government regulatory budget and the number of closing price manipulation prosecutions in the previous year. Government regulatory budgets, in our case the budgets of the SEC and the Ontario Securities Commission, determine the amount of resources available to conduct investigations and prepare cases for prosecution. Therefore, larger regulatory budgets are likely to be associated with greater capacity to prosecute manipulation. ${ }^{8}$ The number of closing price manipulation prosecutions measures the effectiveness and experience of the regulator in detecting and prosecuting closing price manipulation.

Closing price manipulation is more likely to be directly detected when it causes abnormal trading characteristics that trigger alerts in automated market surveillance systems. The measures of abnormal trading characteristics that we use are abnormal day-end return, order imbalance at the end of the day (the amount of buyer initiated trading in excess of seller initiated trading), and price reversion (the return from the closing price to the following morning's price). ${ }^{9}$ Manipulation affects these trading characteristics because in attempting to

\footnotetext{
${ }^{8}$ Stock exchanges also have responsibility for manipulation surveillance, so government regulatory budget only measures part of the total amount spent on regulation and enforcement. Despite this, government budgets are reasonable proxies for the total enforcement effort because as DeMarzo et al. (2005) illustrate self-regulatory organizations are likely to take into consideration the level of government-level regulation and set their enforcement at a level that is just enough to pre-empt government enforcement. A potential problem with this measure of regulator budget is that it is endogenous, i.e., government regulatory budgets are increased in times or countries where manipulation is more widespread. The consequence of this potential endogeneity is to underestimate regulation's deterrence effect on manipulation.

${ }^{9}$ Abnormal day-end trading characteristics can also occur for many reasons other than manipulation, such as news arrivals at the end of the day. These other causes of abnormal trading do not invalidate its relation with detection of manipulation because regardless of the cause, abnormal trading that triggers alerts in
} 
influence the closing price manipulators typically buy or sell heavily in the last minutes before the close creating a liquidity imbalance (e.g., Comerton-Forde and Putniņšs, 2011b), which may in turn induce other market participants to trade. ${ }^{10}$ Given overnight for new orders to enter the market and resolve the imbalance, prices often revert towards their original levels the following morning (e.g., Carhart et al., 2002).

Many instances of manipulation, however, do not create the abnormal trading characteristics that trigger alerts, but can be detected through investigations of other instances of manipulation or investor complaints. Such indirect detection is more likely if unusual trading patterns exist in near proximity (e.g., nearby days in the same stock) because the probability of an alert and subsequent investigation is higher. Therefore, as determinants of indirect detection, we include measures of abnormal trading aggregated through time in a particular stock. ${ }^{11}$ In the two-equation model the direct and indirect detection variables are combined into a single detection equation, thereby reducing the potential problem of weak identification of direct and indirect detection.

\section{$<$ Table III here $>$}

market surveillance systems draws the attention of the regulator and therefore increases the probability that manipulation is detected. Further, manipulation that is accompanied by abnormal trading characteristics such as price spikes and reversals, are more likely to be prosecuted (a process, which in our model is combined with detection) because one of the elements in proving manipulation in court is artificiality in prices or volumes, i.e., a distortion from 'natural' market characteristics.

${ }^{10}$ Manipulation can also be conducted using quotes to provide misleading signals of intentions to trade. Such forms of manipulation are also illegal and, if successful, are likely to be associated with similar characteristics, such as abnormal returns, increased volume and price reversion.

${ }^{11}$ We also construct measures of abnormal trading on a particular day aggregated across all stocks on the corresponding exchange, but find no relation with the probability of indirect detection. 
Table III specifies the variables in each equation. We use two approaches to address the fact that many variables influence both manipulation and detection. In models without expectations simultaneity (Models 1 and 2) we include some variables in both equations, for example, regulatory budget and number of manipulation prosecutions. These variables measure the capacity and effectiveness of the regulator and, at the same time, affect the manipulator's perceived probability of being caught. The abnormal trading characteristics are not observed at the time a manipulator makes the decision to manipulate; they are observed only after the market close or during the following day and are therefore naturally excluded from the manipulation decision equation, thereby contributing to identification. ${ }^{12}$ None of the primary determinants of manipulation are included in the detection equation. In this regard the regulators in the first two models are somewhat naïve in that they do not take advantage of all the information available to them about the determinants of manipulation. However, the third model, which includes the probability of manipulation as a determinant of

\footnotetext{
${ }^{12}$ Excluding the abnormal trading characteristics from the manipulation decision equation does not suggest that manipulators do not consider the impact of their trading on market characteristics such as price. Suppose a manipulator has the choice of trading aggressively, moderately, or not at all and the expected price impacts of the three choices are $4 \%, 2 \%$ and $0 \%$, respectively. In the absence of market surveillance the manipulator might choose to trade aggressively; in the presence of moderate surveillance, the manipulator might scale back and trade moderately, and in the presence of very strong surveillance the manipulator may choose not to manipulate. The manipulator's choice of trading strategy depends on the strength of surveillance and how the potential price impacts that the manipulator could create affect the probability of being detected/prosecuted. Once a manipulator chooses a trading strategy his actions cause actual (observable) trading characteristics. The actual trading characteristics depend on the manipulator's actions but are not a determinant of the manipulator's actions and are therefore not included in the manipulation equation, which consists of determinants of manipulation. To test the sensitivity of our results to this argument we also estimate the models without abnormal return and with abnormal return in the manipulation equation. The results are qualitatively similar to our main results.
} 
the probability of detection, treats regulators as sophisticated in that they are aware of the probability of manipulation and use this information in their detection processes.

We test the key over-identifying restrictions using likelihood ratio tests as described by Dhrymes (1994). We use the approach of Kadane (1974) to sequentially test blocks of exclusion restrictions. ${ }^{13}$ All of the tests fail to reject the null hypothesis that the exclusion restriction is valid, thereby supporting the theoretical motivation of our model specification and the requirements for identification of the models.

\section{Data}

We construct samples of prosecuted closing price manipulation cases (events) and stock-days in which no manipulation is detected or prosecuted (non-events) using endogenous stratified sampling. Due to the rare nature of events, we collect all available events and only a fraction of non-events. ${ }^{14}$

We manually collect all of the closing price manipulation cases detected and prosecuted by market regulators in the US and Canada in the period 1 January 1997 to 1 January 2009. We systematically identify the cases from searches of the litigation releases and filings of the market regulators SEC, OSC, RS, IDA, MFDA, IIROC, NYSE Reg and

\footnotetext{
${ }^{13}$ Specifically, we test the exclusion of: (i) abnormal trading characteristics from the manipulation equation (Models 1, 2, 3); (ii) abnormal trading characteristics from the indirect detection equation (Models 1, 3); (iii) time-series aggregates of abnormal trading characteristics from the manipulation equation (Models 1, 2, 3); (iv) time-series aggregates of abnormal trading characteristics from the direct detection equation (Models 1,3); and (v) all of the above exclusions simultaneously.

${ }^{14}$ Endogenous stratified sampling is widely used to increase the precision of estimates (Cameron and Trivedi, 2005) and mitigate potential biases that can result from rare events (King and Zeng, 2001).
} 
AMEX DRC ${ }^{15}$ and searches of the legal databases Lexis, Quicklaw and Westlaw. From the appendices of SEC annual reports we obtain lists of the case names and filing dates of all the instances of market manipulation against which the SEC took legal action in the fiscal years 1997 to 2005 . We manually examine the litigation releases of each case in these lists to identify instances of closing price manipulation. For cases in which insufficient details are provided by the market regulators we obtain court records and filings through the Administrative Office of the US Courts using the PACER service.

We eliminate cases from our sample if: (i) insufficient information is available to determine which stocks were manipulated on which days; (ii) the manipulation occurred in an over-the-counter market; (iii) the manipulated securities were not common stock; (iv) the manipulation did not involve trade-based techniques; (v) trade and quote data are not available; or (vi) the manipulated stocks do not have at least three months of trading prior to the start of manipulation. ${ }^{16}$ The final sample of detected and prosecuted closing price manipulation is composed of 184 instances of manipulation with complete data. These 184 instances of a stock manipulated on a particular day are obtained from eight independent legal cases, each containing multiple instances of closing price manipulation.

The prosecuted instances of closing price manipulation involve 31 stocks from four exchanges: NYSE, AMEX, TSX and TSX-V. Although we examine litigation releases and filings between 1997 and 2009, the first and last instances of manipulation in our sample

${ }^{15}$ The full names of these regulators are US Securities and Exchange Commission (USA), Ontario Securities Commission (Canada), Market Regulation Services Inc. (Canada), Investment Dealers Association (Canada), Mutual Funds Dealers Association (Canada), Investment Industry Regulatory Organization of Canada (Canada), NYSE Regulation Inc. (USA) and AMEX Division of Regulation and Compliance (USA), respectively.

${ }^{16}$ Although cases in which insufficient information is available to determine the manipulated stock and date cannot be included in the manipulation sample, they are included in the population count of prosecuted manipulation. Consequently, these cases affect the estimates via their influence on the observation weights. 
occur in 1998 and 2005, respectively. The difference between the date of the last examined litigation release and filing and the date of the last instance of manipulation reflects the significant amount of time between when an instance of manipulation occurs and when it is finally prosecuted. The case names, alleged misconduct and legal outcomes are described in Appendix C. There is considerable variation in the manipulation cases with regard to the manipulator (e.g., fund manager, corporate insider, broker, shareholder, proprietary trader) and the motivation for manipulation.

To obtain the sample in which manipulation is not detected and not prosecuted, for each manipulated stock-day we take all other stock-days on the corresponding exchange in a period of one month up to and including the manipulation date. After eliminating stock-days with missing or erroneous data, this sample includes $1,249,748$ observations.

We obtain intra-day trade and quote data, expiry dates for listed options, and index composition data from the Thomson Reuters Tick History database maintained by the Securities Industry Research Centre of Asia-Pacific (SIRCA). We obtain the remaining data from Thomson Reuters Datastream, Thomson Reuters Mutual Fund Database, Thomson Reuters SDC Platinum and the websites of the regulators. We apply normalizing transformations to the data as documented in Table II.

$<$ Table IV here $>$

Table IV reports means, standard deviations and medians of the variables for the sample of prosecuted closing price manipulations and the sample that does not contain prosecuted manipulation. Ignoring the biases due to incomplete detection for now, the difference in means and medians between the two samples is consistent with our expectations for most variables. The sample of detected and prosecuted manipulation involves less liquid stocks (lower market capitalization, turnover, larger spreads and higher ILLIQ), lower levels of institutional following (less analyst forecasts, index constituency and mutual fund 
holdings), and lower idiosyncratic volatility. Manipulation is more concentrated on monthend and quarter-end days, as well as one-month periods prior to secondary equity offerings. The detected manipulation sample is also associated with lower government regulatory budgets, higher abnormal returns, greater price reversion and larger positive order imbalances, as well as higher aggregate levels of the abnormal trading variables on other days in the same stock.

\section{Results}

First we present the estimated model coefficients and discuss the determinants of manipulation and detection. Next, we use our models to estimate the frequency of manipulation and detection. Finally, we report results of robustness tests.

\subsection{THE DETERMINANTS OF MANIPULATION AND DETECTION}

We use two approaches to select variables for the final models from the large number of potential variables and alternative measures (e.g., the several proxies for liquidity). In the first approach we include all of the variables suggested by theory (as specified in Table III), then remove insignificant variables and re-estimate the models. The second approach is a forward stepwise variable selection procedure. ${ }^{17}$ Both approaches give similar sets of variables so we only report the results from the first procedure. For robustness we also estimate models with alternative sets of variables including those not deemed to be significant by the stepwise procedure.

\footnotetext{
${ }^{17}$ Starting with just the constant terms, in each iteration we add variables that result in the largest increase in log-likelihood and re-estimate the model. This is repeated until additional variables do not yield a significant improvement in the log-likelihood. The stepwise variable selection procedures result in a relatively large proportion of statistically significant coefficients because highly statistically insignificant variables are not included in the final specifications.
} 
Table $\mathrm{V}$ reports the coefficient estimates and marginal effects (in parentheses). ${ }^{18}$ For continuous variables, the marginal effects measure the percentage change in the probability of either manipulation, direct or indirect detection for a one percent change in the value of the independent variable. The statistical significance of results in Table V assumes observations are independent. Because the 184 instances of prosecuted manipulation in our sample are related to eight legal cases, the level of statistical significance reported in Table V is likely to be inflated. Therefore, we place more emphasis on the economic significance of the magnitudes. In robustness tests we apply a block-bootstrap procedure (to a subset of the sample due to computational constraints) that accounts for the relations between instances of prosecuted manipulation. These tests suggest that although statistical significance in Table V may be inflated most variables in our model are statistically significant.

\section{$<$ Table V here $>$}

We find that government regulatory budget has a strong effect on both manipulation and detection. Across all three models larger government regulatory budgets increase the probability of detecting and prosecuting manipulation and also decrease the probability of manipulation. The latter effect is likely to be because increased regulatory capacity has a deterrence effect on manipulation. This is consistent with the conclusions made by Pirrong (1995) based on a historical overview of manipulation under various regulatory regimes. We estimate that a $1 \%$ increase in a government regulator's real budget per stock results in a

18 Marginal effects are calculated as $\frac{\partial \operatorname{Pr}}{\partial X}=\frac{\beta^{*} e^{\beta^{*} X}}{\left(1+e^{\beta^{*} X}\right)^{2}}$, where: $\operatorname{Pr}$ is the estimated probability of manipulation, direct detection and indirect detection; $\beta^{*}$ are the coefficient estimates; and $X$ are the observed variable values. They are reported as a percentage of Pr. Marginal effects are calculated for each observation and then averaged over the entire sample. 
$2.0 \%$ decrease in the amount of closing price manipulation and a $1.5 \%$ increase in the rate of prosecution. ${ }^{19}$ Because our models include dummy variables for each of the markets, the effect of budget on manipulation and detection is identified primarily through its time series variation. ${ }^{20}$ The Pearson correlation coefficients between real per-stock government regulatory budget and the number of closing price manipulation prosecutions filed by the regulator in a rolling one-year window are 0.81 and 0.47 in the US and Canada, respectively. This further illustrates the strong association between regulatory budgets and the probability of detection. Real per-stock regulatory budgets in both the US and Canada have steadily increased during the past decade, increasing the probability of detection and putting downward pressure on the rate of manipulation.

The coefficients of the number of analyst forecasts and the index constituency dummy suggest that stocks with greater information asymmetry are more likely to be manipulated. A $20 \%$ reduction in the number of analysts' forecasts is estimated to increase the probability of manipulation by approximately 4\%. This finding holds across all three models and the two information asymmetry variables make the largest contribution to maximizing the model likelihood. This result is consistent with theory (e.g., Allen and Gale, 1992; Kumar and Seppi, 1992; and Aggarwal and Wu, 2006): information asymmetry makes it difficult for market participants to identify whether an aggressive buyer is an informed trader or a manipulator.

Analysts, together with institutional investors, may constrain manipulation by corporate insiders through stronger monitoring of insiders' actions. Consistent with this

\footnotetext{
${ }^{19}$ The former estimate is the average marginal effect across the three models and the later is from Model 2. Because Model 2 aggregates direct and indirect detection, it provides a single estimate for the effect of budget on the total amount of detection (direct and indirect). Models 1 and 3 provide separate estimates for the effect of budget on direct and indirect detection.

${ }^{20}$ There is significant time series variation in regulator budgets. In both the US and Canada the maximum value of real budget per stock is more than twice the minimum.
} 
explanation, in addition to the negative relation between analyst coverage and manipulation, we also find a negative relation between mutual fund ownership and the propensity for manipulation. A one standard deviation increase from the average mutual fund ownership (as a percentage of shares outstanding) is associated with an expected $9 \%$ decrease in the probability of manipulation.

The coefficients of the liquidity and illiquidity variables, market capitalization and ILLIQ, are positive and negative, respectively. ${ }^{21}$ The interpretation of this result is not straightforward. The liquidity variables are correlated with the asymmetric information proxies. Therefore, highly liquid stocks, which also tend to have low information asymmetry, are given a low probability of manipulation by the information asymmetry variables. The positive (negative) coefficient of the liquidity (illiquidity) variable therefore suggests that manipulators do not favor the most illiquid stocks. Taken together, the information asymmetry and liquidity coefficients suggest that manipulators generally prefer stocks that are at neither end of the liquidity spectrum. To confirm this interpretation we reestimate the models replacing the continuous liquidity variables with quintile dummy variables. We find that the probability of manipulation is highest for stocks in the third and fourth quintiles where the first quintile is defined as having the highest liquidity. We conclude that manipulators favor stocks with mid to low levels of liquidity.

A likely explanation of the previous result is that highly liquid stocks are difficult to manipulate because of the high levels of trading activity, substantial order book depth and low information asymmetry. Very illiquid stocks tend not to be favored by manipulators because they generally lack the incentives or magnitude of potential profits that mid-range and highly liquid stocks have. For example, fund managers, in general, hold relatively liquid stocks and any illiquid stocks they may hold only represent a small proportion of their portfolios. Therefore, manipulating the closing prices of very illiquid stocks is unlikely to give fund managers much benefit in overstating their portfolio's performance. Similarly,

\footnotetext{
${ }^{21}$ Using spread as an alternative measure of liquidity produces similar results.
} 
derivatives are less frequently available on very illiquid stocks and such stocks are typically not constituents of major indices. Finally, brokers are more likely to manipulate stocks for the purpose of altering their clients' inference of their execution ability when the clients and orders are large. This seldom occurs in very illiquid stocks.

The results in Table $\mathrm{V}$ also indicate that stocks are significantly more likely to be manipulated on month-end and quarter-end days. Carhart et al. (2002) present evidence that stock price manipulation on month-end and quarter-end days is largely attributable to fund managers. Consistent with this explanation, the coefficients of the interaction terms involving month/quarter-end dummy variables and fund holdings are positive and statistically significant indicating that a high proportion of mutual fund ownership increases the likelihood that a stock is manipulated at month/quarter end. Therefore, our results suggest that fund managers are associated with a significant proportion of all manipulation.

On the other hand, the listed options dummy variables are not statistically significant in our model. Because options tend to be listed on relatively liquid stocks, we do not rule out the possibility that options do affect manipulation but that this effect is overshadowed by the liquidity variables. Whether a stock's price has been increasing or decreasing over the prior month does not have a significant effect on the likelihood of manipulation. Similarly we do not find statistical evidence of a relationship between secondary equity offerings and closing price manipulation.

All else equal, idiosyncratic volatility reduces the likelihood of manipulation. A $20 \%$ increase in the standard deviation of daily return residuals is estimated to decrease the probability of manipulation by $9 \%$. Because idiosyncratic volatility is negatively correlated with liquidity, it is important to note that this estimate is the expected effect when holding liquidity constant. ${ }^{22}$ This finding is consistent with the explanation that idiosyncratic

${ }^{22}$ The correlation between idiosyncratic volatility and the liquidity proxies (market capitalization and turnover) is between -0.43 and -0.50 . The correlation between idiosyncratic volatility and the illiquidity proxies (bid-ask spread and ILLIQ) is between 0.51 and 0.71 . 
volatility deters manipulation because it increases the probability of an alert and subsequent regulatory investigation. The negative relation could also be because, all else equal, stocks with high idiosyncratic volatility increase the risk to the manipulator that the stock price will move against them.

Turning to the variables that affect detection, in all three models the abnormal trading characteristics (abnormal return, reversion and order imbalance) increase the probability of direct detection. The type of market closing mechanism is likely to affect the timing of manipulation-induced abnormal trading characteristics. We therefore examine various dayend windows $(60,30,10$ and 5 minutes before the close) and find that the results are consistent across the alternative lengths. ${ }^{23}$

Indirect detection of manipulation in a particular stock-day is more likely when there is abnormal trading in that stock during a period of a few days either side of that day. In particular, an instance of manipulation that is accompanied by a number of abnormal day-end returns and overnight price reversions in a period of two weeks has an increased probability of being indirectly detected. The regulator notices the abnormal patterns in returns and upon investigation reveals instances of manipulation that did not trigger alerts in surveillance

\footnotetext{
${ }^{23}$ In our sample the Canadian exchanges, TSX and TSX-V, have simple closing mechanisms: trade occurs continuously until $4: 00 \mathrm{pm}$ at which time the market closes and the closing price is the price of the last trade. The TSX introduced a closing call auction for some stocks, with a staggered implementation from March 2004. This does not affect any of the observations in our sample because there are no prosecuted manipulation cases on the TSX after the introduction of the closing call auction. The TSX-V introduced a closing call auction for some stocks from December 2011, after the end of our sample period. The closing mechanisms on the NYSE and AMEX allow orders to be specified for execution at the closing price and the specialists intervene in setting closing prices. Although the NYSE and AMEX closing procedures are sometimes described as auctions, they bear little resemblance to any other auction procedure (Hasbrouck, 2007), particularly automated closing call auctions, such as the ones currently used at Euronext Paris and the London Stock Exchange, for example.
} 
systems. Combining direct and indirect detection into a single detection process, as in the two-equation model, produces similar results regarding the effect of the abnormal trading characteristics on the probability of detection.

The results from Model 3 suggest that ceteris paribus, i.e., after controlling for things such as the effect of abnormal trading characteristics on detection, the probability of detection increases as the probability of manipulation increases. A positive relation suggests that regulators are aware of factors that influence the probability of manipulation and that they use this knowledge in detecting, investigating and prosecuting manipulation. Adding the expectation simultaneity term in Model 3 does not substantially change the conclusions about the other determinants of manipulation and detection.

The exchange dummy variables are included in all equations to allow for different levels of manipulation and detection in each of the two countries (US and Canada) or in different exchanges within a country. Industry dummy variables on the other hand are not included in the final models as they are generally not statistically significant. The pseudo $\mathrm{R}^{2}$ of the models, based on McFadden's likelihood ratio (one minus the ratio of the loglikelihood with all predictors and the log-likelihood with intercepts only) range from 0.17 to 0.23

\subsection{THE FREQUENCY OF MANIPULATION AND DETECTION}

The three models of manipulation and detection allow estimation of the underlying rate of manipulation (detected and not detected) and the fraction of manipulation that remains

undetected. Denoting the parameter estimates by $\beta_{1}^{*}, \beta_{2}^{*}$ and $\beta_{3}^{*}$, applying Bayes's law for the three-equation models gives the probability of an undetected manipulated closing price in the sample with no detected or prosecuted manipulation $\left(\operatorname{set} \mathrm{A}^{\mathrm{c}}\right)$ as: 


$$
\operatorname{Pr}\left(Y_{1 i}=1 \mid Y_{2 i}=0, Y_{3 i}=0\right)=\frac{M\left(X_{1 i} \beta_{1}^{*}\right)\left[1-D\left(X_{2 i} \beta_{2}^{*}\right)-D\left(X_{2 i} \beta_{2}^{*}\right) I\left(X_{3 i} \beta_{3}^{*}\right)\right]}{1-M\left(X_{1 i} \beta_{1}^{*}\right) D\left(X_{2 i} \beta_{2}^{*}\right)-M\left(X_{1 i} \beta_{1}^{*}\right)\left[1-D\left(X_{2 i} \beta_{2}^{*}\right)\right] I\left(X_{3 i} \beta_{3}^{*}\right)}
$$

where $M(), D()$ and $I()$ are defined in Appendix A as the probabilities for manipulation, direct detection and indirect detection, respectively. For the two-equation model the probability of an undetected manipulated closing price in set $\mathrm{A}^{\mathrm{c}}$ is:

$$
\operatorname{Pr}\left(Y_{1 i}=1 \mid Y_{2 i}=0\right)=\frac{M\left(X_{1 i} \beta_{1}^{*}\right)\left[1-D\left(X_{2 i} \beta_{2}^{*}\right)\right]}{1-M\left(X_{1 i} \beta_{1}^{*}\right) D\left(X_{2 i} \beta_{2}^{*}\right)}
$$

These estimates of the probability of manipulation (given that manipulation has not been prosecuted) are useful in efficiently allocating regulators' resources, particularly when resources are increased and it becomes possible to investigate additional cases of suspected manipulation. These probability estimates can also be used to study the characteristics of undetected or not prosecuted closing price manipulation.

Using a similar approach to Feinstein (1990), the fraction of undetected manipulation in the population can be consistently estimated as:

$$
\left(\frac{N}{T n}\right) \sum_{i \in A^{c}} \operatorname{Pr}\left(Y_{1 i}=1 \mid Y_{2 i}=0, Y_{3 i}=0\right)
$$

where $T$ is the total number of observations in the population (the sum of the number of observations in sets $\mathrm{A}$ and $\mathrm{A}^{\mathrm{c}}$ ), $N$ is the population number of observations in set $\mathrm{A}^{\mathrm{c}}$ and $n$ is the sample number of observations in set $\mathrm{A}^{\mathrm{c}}$.

Models 1 and 2 estimate the fraction of undetected closing price manipulation in the population as $1.14 \%$ and $1.08 \%$ of all stock-days, respectively. The rate of detected and prosecuted manipulation in the population (number of observations in set A divided by T) is $0.004 \%$. This suggests that there are many more instances of manipulation not prosecuted than there are prosecuted manipulations. In fact, these estimates suggest that only about $0.4 \%$ of all manipulation is prosecuted. For every prosecuted closing price manipulation approximately 308 to 326 manipulations remain either undetected or not prosecuted. Here 
the limitation of modeling detection and prosecution together becomes clear - we cannot infer the fraction of the not prosecuted manipulation that was detected. Adding the rates of prosecuted and not prosecuted manipulation, the underlying rate of manipulation in the population is estimated at $1.14 \%$ to $1.08 \%$ of stock-days. This is not significantly different from the rate of manipulation that is not prosecuted, because only a small fraction of manipulation is prosecuted.

What explains the large difference between the total amount of manipulation and the amount of prosecuted manipulation? We believe there are two main factors. First, discussions with regulators and other anecdotal evidence indicate that a significant proportion of the manipulation detected by regulators is not prosecuted. One of the main reasons for this is difficulty in obtaining sufficiently incriminating evidence. Given that many nonmanipulative motivations for trading can lead to the same pattern of trades and market impact as manipulation, what distinguishes manipulative from non-manipulative trading is manipulative intent (see, for example, Ledgerwood and Carpenter, 2012). In practice, proving manipulative intent often requires recorded telephone conversations or intercepted emails, which contain explicit statements of the manipulator's intent. In place of formal legal action, in some instances regulators with insufficient evidence simply warn the suspected manipulators about their suspicious trading patterns, thereby hoping to stop further manipulation. As DeMarzo et al. (1998) point out, optimal enforcement must balance the benefits of enforcement against the costs, which in practice can be substantial, and therefore it is often optimal to pursue only a fraction of the possible cases.

Second, many instances of manipulation are very difficult to detect. Given the significant penalties for convicted manipulation (criminal charges) it is reasonable to expect that manipulators will only choose to do so when the probability of detection and prosecution is low. To reduce the probability of detection manipulators scale back the aggressiveness of their trading and alter the timing of their trades to conceal their actions from the regulator (Comerton-Forde and Putniņš, 2011b). Consistent with this explanation we find that: (i) 
many instances of closing price manipulation do not cause easily detectable abnormal trading characteristics; and (ii) manipulation tends to take place when the probability of detection is exceptionally low. For example, our prosecuted manipulation sample contains instances of zero or negative day-end returns despite the manipulator's intent to increase the closing price. Similarly, in unreported results the day-end characteristics of a sub-sample consisting of the top $1 \%$ of stock-days by manipulation probability (estimated with the DCE Model 1) are not significantly different from those of other stock-days. Furthermore, the average probability of direct (indirect) detection for the top $1 \%$ of stock-days by manipulation probability is only $0.06 \%(0.00002 \%)$, whereas for other stock days it is $4.5 \%(5.6 \%)$. Therefore, the low detection and prosecution rates are largely explained by the difficulties in detecting manipulation due to manipulators concealing their actions given the large potential penalties, and difficulties in proving manipulative intent once suspected manipulation has been identified.

\subsection{ROBUSTNESS AND VALIDATION TESTS}

We examine the robustness of our results. In our initial implementation, the disturbance terms, $\varepsilon_{1 i}, \varepsilon_{2 i}$ and $\varepsilon_{3 i}$, are assumed to be drawn from independent standard logistic distributions with probability density function $f(\varepsilon)=\frac{e^{-\varepsilon}}{\left(1+e^{-\varepsilon}\right)^{2}}$. To test the sensitivity of our results to this assumption we estimate the models using four alternative disturbance term distributions with fatter tails, thinner tails, a right skew and a left skew. ${ }^{24}$

\footnotetext{
${ }^{24}$ The fat and thin tailed distributions are equal mixtures of a standard logistic distribution and a logistic distribution with larger or smaller scale parameter respectively. Their probability density functions are given by $f(\varepsilon)=\frac{e^{-\varepsilon}}{2\left(1+e^{-\varepsilon}\right)^{2}}+\frac{e^{-\varepsilon / s}}{2 s\left(1+e^{-\varepsilon / s}\right)^{2}}$ with $s=2$ for the fat tailed distribution and $s=0.5$ for the thin tailed distribution. The right and left skew distributions are generalized logistic distributions with
} 
The marginal effects of most independent variables are very similar under the different disturbance term distributions, suggesting the results are not overly sensitive to the assumed disturbance term distribution.

The statistical significance of our main results may be affected by dependencies between observations causing clustering of errors. This can occur due to manipulators targeting particular stocks or days multiple times, or due to our 184 instances of prosecuted manipulation being related to eight legal cases. To address this concern we implement two versions of the bootstrap algorithm described in Cameron et al. (2011): (i) clustering standard errors by stock and by date (double clustering); and (ii) clustering standard errors by legal case. The first version provides consistent standard errors under arbitrary two-way error clustering within stocks and dates and the second accounts for relations between observations related to the same legal case. We run 500 repetitions of each bootstrap estimation. Due to computational constraints we use a sample consisting of all of the detected manipulation observations and randomly selected $1 \%$ of the stock-days with no detected manipulation, adjusting observation weights accordingly.

Nonlinear maximum likelihood estimators can be biased in finite samples. Although our total sample size is large, the number of manipulation and detection observations is relatively small due to the rare nature of these events. ${ }^{25}$ We examine the potential influence of finite-sample biases by estimating the bootstrap bias-corrected parameter estimates suggested by Efron and Tibsharani (1993) and Cameron and Trivedi (2005). The difference

probability density $f(\varepsilon)=\frac{b e^{-\varepsilon}}{\left(1+e^{-\varepsilon}\right)^{(b+1)}}$ and $b=2$ for the right skew distribution and $b=0.5$ for the left skew distribution.

${ }^{25}$ King and Zeng (2001) document a special case of the finite sample bias for rare events in logistic regression. However, their results are not directly applicable to DCE models consisting of multiple simultaneous equations. 
between the bias-corrected estimates and uncorrected estimates allow us to gauge the magnitude of the potential bias.

\section{$<$ Table VI here $>$}

Table VI reports the results of the bootstrap-based corrections for double-clustered errors and finite-sample bias. The coefficient and marginal effect estimates using the reduced size sample are similar to those estimated using the full sample. Despite the fact that the cluster-robust standard errors are larger on average, most coefficients remain statistically significant at the $1 \%$ level. Similarly, the statistical significance when standard errors are clustered by legal case (results available upon request) is lower, but most of the variables remain statistically significant. The bias-corrected estimates are similar to those without correction, suggesting finite-sample bias does not have a large influence on our estimates.

We also examine the robustness of our results to changes in the sample composition, the time period from which the sample is drawn, different model specifications and alternative variable definitions. To test the sensitivity to the particular sample and time period we split our data into two sub-samples, first by time (earliest half of the data and latest half of the data) and then randomly, and estimate the model separately on each sub-sample. We also re-estimate our model using only post-decimalization data. We test alternative model specifications by including the variables from Table II that are left out of the reported models. We examine the sensitivity of the results to the way the variables are measured by replacing variables with their alternative definitions given in Table II. We find that the main results hold in each of these robustness tests and therefore we do not report these results.

We conduct three simple validity tests of the main econometric model's predictions. First, we expect manipulation to cluster on particular days and in particular stocks that are manipulated repeatedly. Using the top $1 \%$ of predicted manipulation probabilities as a proxy for manipulated closing prices we examine the distribution of predicted manipulation across stocks and dates. The distribution is far from uniform with pronounced clustering in 
particular stocks and on particular dates, as expected. This result holds even after excluding month-end and quarter-end days. Second, we examine whether the model predicts manipulation in the lead up to prosecuted instances using a probit regression with prosecuted manipulation as the dependent variable and a dummy variable for whether the model predicts manipulation in a rolling window containing the past week as the independent variable. We obtain a positive and statistically significant coefficient on the independent variable suggesting the model predicts manipulation in the week leading up to prosecuted instances of manipulation.

The third test is a form of leave-one-out cross-validation of out-of-sample predictive accuracy. For each of the eight legal cases in turn we: (i) remove the case (and corresponding non-manipulated stock-days) from the sample; (ii) estimate the main DCE model (Model 1) on the remaining data; and (iii) use the model estimates to calculate for each closing price in the left out data the predicted probability that the closing price falls into the set of prosecuted manipulations (the probability that the closing price is manipulated and either directly or indirectly detected). We examine the accuracy of the predicted probabilities using Receiver Operating Characteristics (ROC) analysis. The Area Under the ROC curve (AUROC) measures the probability of correct prediction, independent of prior probabilities and classification thresholds. Hosmer and Lemeshow (2000) suggest the following interpretation of AUROC values: around 0.5 implies the model performs no better than chance; 0.7-0.8 implies acceptable classification performance; 0.8-0.9 implies excellent performance; and 0.9-1.0 implies outstanding performance (rare). For our main model the out-of-sample AUROC point estimate is 0.902 , with a $95 \%$ confidence interval 0.870 to 0.934 . These results suggest our DCE model has excellent out-of-sample classification accuracy, supporting the validity of the model. 


\section{Conclusions}

We examine the determinants of manipulation and its detection using methods that recognize that only a non-random subset of manipulation is detected and prosecuted. Stocks with high levels of information asymmetry and mid to low levels of liquidity are most likely to be manipulated. The probability of manipulation is higher on month-end and quarter-end days, particularly for stocks with relatively high levels of mutual fund ownership, suggesting fund managers account for a significant proportion of manipulation. All else equal, manipulators dislike stocks with high levels of idiosyncratic volatility, possibly because of the risk that the stock will move against them or due to the increased likelihood of the stock triggering alerts and attracting the attention of a regulator. Larger government regulatory budgets increase the rate of prosecution and significantly deter manipulation. These insights help understand the underpinnings of closing price manipulation and allow regulatory effort to be focused where manipulation is most likely to occur.

We also find that only a small fraction of manipulation is detected and prosecuted. For each instance of prosecuted closing price manipulation we estimate that approximately 308 to 326 instances of manipulation remain undetected or not prosecuted. The amount of manipulation can be reduced by allocating additional resources to regulation. The results suggest that a $1 \%$ increase in government regulatory budgets would result in an estimated $2.0 \%$ decrease in the amount of closing price manipulation and a $1.5 \%$ increase in the rate of

prosecution. These estimates should be taken into account by policymakers when deciding on how much resources to allocate to regulation because as pointed out by DeMarzo et al. (1998) the socially optimal amount of enforcement depends on the frequency of violations and how violators, in our case manipulators, respond to increased enforcement.

All statistical methods are subject to some degree of estimation error and more difficult to quantify model error. The statistical method used in this paper is no exception. Analogous to the way practitioners estimate the value of a company by using multiple 
methods and taking the average or a range from the various estimates, we hope that future research will use alternative methods to estimate the prevalence of closing price manipulation, its determinants and how it responds to regulation. Estimates from alternative methods will help reduce the uncertainty about model error and therefore increase confidence in the estimates. As highlighted by this paper, it is important that methods explicitly address the problem of incomplete detection in order to avoid potentially significant biases in inference.

In future work it would be useful to extend the sample in time (the last instance of manipulation in our sample occurs in 2005, reflecting the time taken to bring cases to prosecution). This would allow examination of how manipulation and detection have responded to several interesting market structure and regulatory changes, such as the introduction of a closing call auction for some stocks on the TSX and TSX-V, Regulation NMS for the US exchanges, and the tendency for surveillance and enforcement roles to shift from self-regulatory organizations such as stock exchanges to more centralized governmentlevel regulators. Finally, this study provides an instrument to calculate the probability of manipulation that has not been prosecuted. This instrument can be used to study the characteristics of undetected manipulation and refine alerting parameters of market surveillance systems. 


\section{Appendix A: Details of Model Estimation Procedure}

We define $M(), D()$ and $I()$ to be monotonic link functions that link $X_{1 i} \beta_{1}, X_{2 i} \beta_{2}$ and $X_{3 i} \beta_{3}$, to latent probabilities for manipulation, direct detection and indirect detection, respectively. ${ }^{26}$ That is,

$$
\begin{aligned}
& M\left(X_{1 i} \beta_{1}\right)=\operatorname{Pr}\left(Y_{1 i}=1\right) \\
& D\left(X_{2 i} \beta_{2}\right)=\operatorname{Pr}\left(Y_{2 i}=1 \mid Y_{1 i}=1\right) \\
& I\left(X_{3 i} \beta_{3}\right)=\operatorname{Pr}\left(Y_{3 i}=1 \mid Y_{1 i}=1, Y_{2 i}=0\right)
\end{aligned}
$$

Table A.I reports the probabilities of an observation (closing price) arriving at various joint outcomes (represented by cells in the table) of the manipulation and detection processes. The joint outcomes are mutually exclusive and exhaustive, so the probabilities in Table A.I sum to one.

\section{Table A.I. Modified detection controlled estimation model probabilities}

This table reports the probabilities of an observation (a closing price) arriving at various outcomes. $M()$ is the probability that a closing price is manipulated. $D()$ is the probability that a manipulated closing price is

\begin{tabular}{|c|c|c|c|}
\hline & & \multicolumn{2}{|c|}{ Manipulation } \\
\hline & & Manipulated & Not manipulated \\
\hline \multirow{3}{*}{ Detection } & Directly detected & $M() D()$ & 0 \\
\hline & Indirectly detected & $M()[1-D()] I()$ & 0 \\
\hline & Not detected & $M()[1-D()][1-I()]$ & $1-M()$ \\
\hline
\end{tabular}
directly detected. $I()$ is the probability that a manipulated closing price is indirectly detected, given that it is not directly detected.

In order to observe a detected manipulated closing price, the closing price must have been manipulated and either directly or indirectly detected. These outcomes correspond to

\footnotetext{
${ }^{26}$ In our implementation of this model the link functions are cumulative logistic distribution functions, that is, $M\left(X_{1 i} \beta_{1}\right)=\frac{1}{1+e^{-X_{1 i} \beta_{1}}}, D\left(X_{2 i} \beta_{2}\right)=\frac{1}{1+e^{-X_{2 i} \beta_{2}}}$ and $I\left(X_{3 i} \beta_{3}\right)=\frac{1}{1+e^{-X_{3 i} \beta_{3}}}$. The disturbance terms, $\varepsilon_{1 i}, \varepsilon_{2 i}$ and $\varepsilon_{3 i}$, are from independent logistic distributions with mean zero and variance $\frac{\pi^{2}}{3}$ (scale parameter of one). In robustness tests we examine alternative distributions for the disturbance term.
} 
the first two probability rows in Table A.I due to the simplifying assumption of no false detection. ${ }^{27}$ Therefore, the log-likelihood of the set of detected manipulated closing prices (set A), is:

$$
\log L_{A}=\sum_{i \in A} \log \left\{M\left(X_{1 i} \beta_{1}\right) D\left(X_{2 i} \beta_{2}\right)+M\left(X_{1 i} \beta_{1}\right)\left[1-D\left(X_{2 i} \beta_{2}\right)\right] I\left(X_{3 i} \beta_{3}\right)\right\}
$$

Similarly, for a closing price in which manipulation has not been detected, either: (i) manipulation has not occurred; or (ii) manipulation has occurred and evaded both direct and indirect detection. These outcomes correspond to third probability row in Table A.I. Therefore, the log-likelihood of the set of observations in which manipulation is not detected $\left(\operatorname{set} A^{c}\right)$ :

$$
\log L_{A^{c}}=\sum_{i \in A^{c}} \log \left\{\left[1-M\left(X_{1 i} \beta_{1}\right)\right]+M\left(X_{1 i} \beta_{1}\right)\left[1-D\left(X_{2 i} \beta_{2}\right)\right]\left[1-I\left(X_{3 i} \beta_{3}\right)\right]\right\}
$$

The log-likelihood of the full sample is the sum of the log-likelihoods of the two sets of observations. To estimate this model with data collected from endogenous stratified sampling (choice-based sampling) we add weights to the observations and the resulting weighted maximum-likelihood estimator (due to Manski and Lerman (1977)) becomes:

$$
\begin{aligned}
& \log L=w_{A} \sum_{i \in A} \log \left\{M\left(X_{1 i} \beta_{1}\right) D\left(X_{2 i} \beta_{2}\right)+M\left(X_{1 i} \beta_{1}\right)\left[1-D\left(X_{2 i} \beta_{2}\right)\right] I\left(X_{3 i} \beta_{3}\right)\right\} \\
& +w_{A^{c}} \sum_{i \in A^{C}} \log \left\{\left[1-M\left(X_{1 i} \beta_{1}\right)\right]+M\left(X_{1 i} \beta_{1}\right)\left[1-D\left(X_{2 i} \beta_{2}\right)\right]\left[1-I\left(X_{3 i} \beta_{3}\right)\right]\right\}
\end{aligned}
$$

where $w_{A}=\tau / s, w_{A^{c}}=(1-\tau) /(1-s)$ and $\tau$ and $s$ are the fractions of stock-days with prosecuted manipulation in the population and sample respectively. Note this weighted estimator does not require knowledge of the underlying rates of manipulation and detection; it merely accounts for the fact that we sample a different proportion of the observations in the observable sets $\mathrm{A}$ and $\mathrm{A}^{\mathrm{c}}$.

\footnotetext{
${ }^{27}$ More precisely, we assume that the probability of detecting and prosecuting manipulation given that manipulation has not occurred is zero. This assumption seems reasonable considering the strength of evidence required to prosecute closing price manipulators.
} 


\section{Appendix B: Alternative Models}

\section{B.1 TWO-EQUATION (STANDARD DCE) MODEL OF MANIPULATION AND} DETECTION

Using the same notation as for the three-equation model and omitting much of the explanation the two-equation model of manipulation and detection is as follows.

$$
\begin{aligned}
& Y_{1 i}^{*}=X_{1 i} \beta_{1}+\varepsilon_{1 i} \\
& Y_{1 i}=\left\{\begin{array}{lll}
1 & \text { (manipulated) } & \text { if } \\
0 & \text { (not) } & \begin{array}{l}
Y_{1 i}^{*}>0 \\
Y_{1 i}^{*} \leq 0
\end{array}
\end{array}\right\} \\
& Y_{2 i}^{*}=X_{2 i} \beta_{2}+\varepsilon_{2 i} \\
& Y_{2 i}=\left\{\begin{array}{llll}
1 & \text { (detected) } \\
0 & \text { (not) } & \text { if } \begin{array}{l}
Y_{2 i}^{*}>0 \\
Y_{2 i}^{*} \leq 0
\end{array}
\end{array}\right\} \\
& M\left(X_{1 i} \beta_{1}\right)=\operatorname{Pr}\left(Y_{1 i}=1\right) \\
& D\left(X_{2 i} \beta_{2}\right)=\operatorname{Pr}\left(Y_{2 i}=1 \mid Y_{1 i}=1\right) \\
& \log L_{A}=\sum_{i \in A} \log \left\{M\left(X_{1 i} \beta_{1}\right) D\left(X_{2 i} \beta_{2}\right)\right\} \\
& \log L_{A^{c}}=\sum_{i \in A^{c}} \log \left\{\left[1-M\left(X_{1 i} \beta_{1}\right)\right]+M\left(X_{1 i} \beta_{1}\right)\left[1-D\left(X_{2 i} \beta_{2}\right)\right]\right\}
\end{aligned}
$$

$\log L=w_{A} \sum_{i \in A} \log \left\{M\left(X_{1 i} \beta_{1}\right) D\left(X_{2 i} \beta_{2}\right)\right\}+w_{A^{c}} \sum_{i \in A^{c}} \log \left\{\left[1-M\left(X_{1 i} \beta_{1}\right)\right]+M\left(X_{1 i} \beta_{1}\right)\left[1-D\left(X_{2 i} \beta_{2}\right)\right]\right\}$

\section{B.2 THREE-EQUATION MODEL OF MANIPULTION AND DETECTION WITH EXPECTATIONS SIMULTANEITY}

$$
\begin{gathered}
Y_{1 i}^{*}=X_{1 i} \beta_{1}+\varepsilon_{1 i} \\
Y_{1 i}=\left\{\begin{array}{ll}
1 & \text { (manipulated) } \\
0 & \text { (not) }
\end{array} \text { if } \begin{array}{c}
Y_{1 i}^{*}>0 \\
Y_{1 i}^{*} \leq 0
\end{array}\right\} \\
M\left(X_{1 i} \beta_{1}\right)=\operatorname{Pr}\left(Y_{1 i}=1\right) \\
Y_{2 i}^{*}=X_{2 i} \beta_{2}+M\left(X_{1 i} \beta_{1}\right) \delta_{2}+\varepsilon_{2 i}
\end{gathered}
$$




$$
\begin{aligned}
& Y_{2 i}=\left\{\begin{array}{lll}
1 & \text { (directly detected) } \\
0 & \text { (not) } & \text { if } \begin{array}{l}
Y_{2 i}^{*}>0 \\
Y_{2 i}^{*} \leq 0
\end{array}
\end{array}\right\} \\
& D\left(X_{2 i} \beta_{2}, M\left(X_{1 i} \beta_{1}\right) \delta_{2}\right)=\operatorname{Pr}\left(Y_{2 i}=1 \mid Y_{1 i}=1\right) \\
& Y_{3 i}^{*}=X_{3 i} \beta_{3}+M\left(X_{1 i} \beta_{1}\right) \delta_{3}+\varepsilon_{3 i}
\end{aligned}
$$

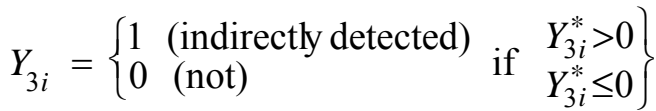

$$
\begin{aligned}
& I\left(X_{3 i} \beta_{3}, M\left(X_{1 i} \beta_{1}\right) \delta_{3}\right)=\operatorname{Pr}\left(Y_{3 i}=1 \mid Y_{1 i}=1, Y_{2 i}=0\right)
\end{aligned}
$$

Representing $M\left(X_{1 i} \beta_{1}\right)$ by $M, D\left(X_{2 i} \beta_{2}, M\left(X_{1 i} \beta_{1}\right) \delta_{2}\right)$ by $D$ and $I\left(X_{3 i} \beta_{3}, M\left(X_{1 i} \beta_{1}\right) \delta_{3}\right)$ by $I$ :

$$
\begin{gathered}
\log L_{A}=\sum_{i \in A} \log \{M D+M[1-D] I\} \\
\log L_{A^{C}}=\sum_{i \in A^{C}} \log \{[1-M]+M[1-D][1-I]\} \\
\log L=w_{A} \sum_{i \in A} \log \{M D+M[1-D] I\}+w_{A^{C}} \sum_{i \in A^{C}} \log \{[1-M]+M[1-D][1-I]\}
\end{gathered}
$$




\section{Appendix C: Summary of Manipulation Cases}

\begin{tabular}{|c|c|c|c|c|}
\hline Case & \begin{tabular}{|c|} 
Period of \\
manipulation
\end{tabular} & Exchange & Alleged misconduct & Outcomes \\
\hline $\begin{array}{l}\text { SEC v. Competitive Technologies, } \\
\text { Inc. et al., Civil Action No. } 304 \text { CV } \\
1331 \text { JCH (District of Connecticut) }\end{array}$ & $\begin{array}{c}\text { 1-Jul-98 } \\
\text { to } \\
\text { 29-Jun-01 }\end{array}$ & AMEX & $\begin{array}{l}\text { A prolonged multi-faceted scheme carried out } \\
\text { by several brokers, former brokers and } \\
\text { company CEO in an attempt for the } \\
\text { manipulators to enrich themselves and avoid } \\
\text { margin calls. }\end{array}$ & $\begin{array}{l}\text { Conviction by a } \\
\text { federal jury and } \\
\text { settlements. }\end{array}$ \\
\hline $\begin{array}{l}\text { In the Matter of RT Capital } \\
\text { Management Inc. et al. }\end{array}$ & $\begin{array}{l}\text { 30-Oct-98 } \\
\text { to } \\
\text { 31-Mar-99 }\end{array}$ & TSX & $\begin{array}{l}\text { Closing price manipulation of several stocks } \\
\text { by several fund managers at the ends of } \\
\text { reporting periods to inflate reported } \\
\text { performance. This enabled the fund to collect } \\
\text { more management fees and earned the fund } \\
\text { managers greater remuneration. }\end{array}$ & $\begin{array}{l}\text { Settlement, } \\
\text { fines and } \\
\text { suspensions. }\end{array}$ \\
\hline $\begin{array}{l}\text { In the Matter of Spear, Leeds \& } \\
\text { Kellogg, L.P., Administrative } \\
\text { Proceeding File No. 3-11189 / In the } \\
\text { Matter of Baron Capital Inc. et al., } \\
\text { Administrative Proceeding File No. } \\
\text { 3-11096 }\end{array}$ & $\begin{array}{l}18-\text { Oct-99 } \\
\text { to } \\
1-\text { Nov-99 }\end{array}$ & NYSE & $\begin{array}{l}\text { Closing price manipulation by a substantial } \\
\text { shareholder during the pricing-period for a } \\
\text { company acquisition. }\end{array}$ & $\begin{array}{l}\text { Settlement and } \\
\text { fines. }\end{array}$ \\
\hline $\begin{array}{l}\text { In the Matter of John Andrew Scott } \\
\text { (OOS 2003-010) / In the Matter of } \\
\text { Linda Grace Malinowski (OOS } \\
\text { 2003-011) / In the Matter of Matthew } \\
\text { Philip Linden (OOS 2003-012) }\end{array}$ & $\begin{array}{l}\text { 2-Feb-00 } \\
\text { to } \\
\text { 4-Jul-00 }\end{array}$ & TSX & $\begin{array}{l}\text { Manipulation of closing prices over a period } \\
\text { of consecutive days in relation to an } \\
\text { application for price protection. }\end{array}$ & $\begin{array}{l}\text { Settlements, } \\
\text { fines and } \\
\text { suspensions. }\end{array}$ \\
\hline $\begin{array}{l}\text { In the Matter of Douglas Christie } \\
\text { (OOS 2002-002) }\end{array}$ & $\begin{array}{l}\text { 28-Feb-01 } \\
\text { to } \\
\text { 29-Jun-01 }\end{array}$ & TSX & $\begin{array}{l}\text { Manipulation of closing prices over a period } \\
\text { of time to increase personal remuneration, } \\
\text { which was paid by the trading firm based on } \\
\text { market value of the trader's inventory balance. }\end{array}$ & $\begin{array}{l}\text { Settlement and } \\
\text { fines. }\end{array}$ \\
\hline $\begin{array}{l}\text { In the Matter of Schultz Investment } \\
\text { Advisors, Inc. and Scott Schultz, } \\
\text { Administrative Proceeding File No. } \\
\text { 3-12136 }\end{array}$ & $\begin{array}{l}\text { 28-Jun-02 } \\
\text { to } \\
\text { 31-Dec-03 }\end{array}$ & NYSE & $\begin{array}{l}\text { Closing price manipulation by a fund manager } \\
\text { at the ends of reporting periods. This was } \\
\text { done to inflate reported performance and } \\
\text { subsequently collect more management fees. }\end{array}$ & $\begin{array}{l}\text { Settlement, fine } \\
\text { and suspension. }\end{array}$ \\
\hline $\begin{array}{l}\text { In the Matter of Alfred Simon } \\
\text { Gregorian (DN 2006-003) / In the } \\
\text { Matter of Research Capital } \\
\text { Corporation (DN 2006-005) }\end{array}$ & $\begin{array}{l}\text { 12-Nov-03 } \\
\text { to } \\
\text { 24-Dec-03 }\end{array}$ & TSX-V & $\begin{array}{l}\text { Manipulation of the closing prices of a single } \\
\text { stock over a period of time to create a } \\
\text { misleading appearance of strength and } \\
\text { stability in the market for the company's } \\
\text { shares. }\end{array}$ & $\begin{array}{l}\text { Settlement, } \\
\text { fines and } \\
\text { suspensions. }\end{array}$ \\
\hline $\begin{array}{l}\text { In the Matter of Luc St Pierre } \\
\text { (IIROC No. 11) }\end{array}$ & $\begin{array}{l}\text { 1-Oct-04 } \\
\text { to } \\
\text { 30-Sep-05 }\end{array}$ & TSX-V & $\begin{array}{l}\text { Manipulation of the closing prices of two } \\
\text { stocks over a period of time on behalf of } \\
\text { anonymous sophisticated investors and a } \\
\text { company director. }\end{array}$ & $\begin{array}{l}\text { Conviction by a } \\
\text { Disciplinary } \\
\text { Panel, fines and } \\
\text { suspension. }\end{array}$ \\
\hline
\end{tabular}




\section{References}

Aggarwal, R.K., and Wu, G. (2006) Stock market manipulations, Journal of Business 79, 1915-1953.

Allen, F., and Gale, D. (1992) Stock-price manipulation, The Review of Financial Studies 5, 503-529.

Allen, F., Litov, L., and Mei, J. (2006) Large investors, price manipulation, and limits to arbitrage: An anatomy of market corners, Review of Finance 10, 645-693.

Amihud, Y. (2002) Illiquidity and stock returns: Cross-section and time-series effects, Journal of Financial Markets 5, 31-56.

Ben-David, I., Franzoni, F., Landier, A., and Moussawi, R. (2011) Do hedge funds manipulate stock prices?, Unpublished working paper, Fisher College of Business.

Bernhardt, D., and Davies, R.J. (2005) Painting the tape: Aggregate evidence, Economics Letters 89, 306-311.

Bernhardt, D., and Davies, R.J. (2009) Smart fund managers? Stupid money?, Canadian Journal of Economics 42, 719-748.

Cameron, A.C., Gelbach, J.B., and Miller, D.L. (2011) Robust inference with multiway clustering, Journal of Business and Economics Statistics 29, 238-249.

Cameron, A.C., and Trivedi, P.K. (2005) Microeconomics: Methods and Applications, Cambridge University Press, New York.

Carhart, M., Kaniel, R., Musto, D., and Reed, A. (2002) Leaning for the tape: Evidence of gaming behavior in equity mutual funds, Journal of Finance 57, 661-693.

Comerton-Forde, C., and Putniņš, T.J. (2011a) Measuring closing price manipulation, Journal of Financial Intermediation 20, 135-158. 
Comerton-Forde, C., and Putniņš, T.J. (2011b) Pricing accuracy, liquidity and trader behavior with closing price manipulation, Experimental Economics 14, 110-131.

Cumming, D., Johan, S., and Li, D. (2011) Exchange trading rules and stock market liquidity, Journal of Financial Economics 99, 651-671.

DeMarzo, P.M., Fishman, M.J., and Hagerty, K.M. (1998) Optimal enforcement of insider trading regulations, Journal of Political Economy 106, 602-632.

DeMarzo, P.M., Fishman, M.J., and Hagerty, K.M. (2005) Self-regulation and government oversight, Review of Economic Studies 72, 687-706.

Dhrymes, P.J. (1994) Topics in advanced econometrics, Volume II: Linear and nonlinear simultaneous equations, Springer-Verlag, New York.

Efron, B., and Tibsharani, J. (1993) An introduction to the bootstrap, Chapman and Hall, London.

Feinstein, J.S. (1989) The safety regulation of U.S. nuclear power plants: Violations, inspections, and abnormal occurrences, The Journal of Political Economy 97, 115-154.

Feinstein, J.S. (1990) Detection controlled estimation, Journal of Law and Economics 33, 233-276.

Feinstein, J.S. (1991) An econometric analysis of income tax evasion and its detection, Rand Journal of Economics 22, 14-35.

Fischel D., and Ross, D. (1991) Should the law prohibit manipulation in financial markets?, Harvard Law Review 105, 503-553.

Goetzmann, W., Ingersoll, J., Spiegel, M., and Welch, I. (2007) Portfolio performance manipulation and manipulation-proof performance measures, Review of Financial Studies 20, 1503-1546.

Hasbrouck, J. (2007) Empirical market microstructure: The institutions, economics and econometrics of securities trading, Oxford University Press, Oxford. 
Hillion, P., and Suominen, M. (2004) The manipulation of closing prices, Journal of Financial Markets 7, 351-375.

Hosmer, D.W., and Lemeshow, S. (2000) Applied logistic regression, $2^{\text {nd }}$ Edition, John Wiley and Sons, New York.

IOSCO (2000) Investigating and prosecuting market manipulation, Technical Committee of the International Organization of Securities Commissions.

Jarrow, R.A. (1994) Derivative security markets, market manipulation, and option pricing theory, The Journal of Financial and Quantitative Analysis 29, 241-261.

Jegadeesh, N. (1993) Treasury auction bids and the Salomon squeeze, Journal of Finance 48, 1403-1419.

Jiang, G., Mahoney, P., and Mei, J. (2005) Market manipulation: A comprehensive study of stock pools, Journal of Financial Economics 77, 147-170.

Jordan, B., and Jordan, S. (1996) Salomon Brothers and the May 1991 Treasury auction: Analysis of a market corner, Journal of Banking and Finance 20, 25-40.

Kadane, J.B. (1974) Testing a subset of the overidentifying restrictions, Econometrica 42, 853-867.

King, G., and Zeng, L. (2001) Logistic regression in rare events data, Political Analysis 9, 137-163.

Kumar, P., and Seppi, D.J. (1992) Futures manipulation with cash settlement, Journal of Finance 47, 1485-1502.

Kyle, A.S., and Viswanathan, S. (2008) How to define illegal price manipulation, American Economic Review 98, 274-279.

Ledgerwood, S.D., and Carpenter, P.R. (2012) A framework for the analysis of market manipulation, Unpublished working paper. 
Mahoney, P. (1999) The stock pools and the Securities Exchange Act, Journal of Financial Economics 51, 343-369.

Manski, C.F, and Lerman, S.R. (1977) The estimation of choice probabilities from choice based samples, Econometrica 45, 1977-1988.

Merrick Jr, J., Naik, N., and Yadav, P. (2005) Strategic trading behavior and price distortion in a manipulated market: Anatomy of a squeeze, Journal of Financial Economics 77, $171-218$.

Ni, S.X., Pearson, N.D., and Poteshman, A.M. (2005) Stock price clustering on option expiration dates, Journal of Financial Economics 78, 49-87.

Pirrong, S.C. (1995) The self-regulation of commodity exchanges: The case of market manipulation, Journal of Law and Economics 38, 141-206.

Poirier, D.J. (1980) Partial observability in bivariate probit models, Journal of Econometrics 12, 209-217.

Stoll, H.R., and Whaley, R.E. (1991) Expiration-day effects: What has changed? Financial Analysts Journal 47, 58-72.

Thel, S. (1994) $\$ 850,000$ in six minutes - The mechanics of securities manipulation, Cornell Law Review 79, 219-298.

Wang, T.Y. (2012) Corporate securities fraud: Insights from a new empirical framework, Journal of Law, Economics, and Organization (forthcoming). 
Table I. Numerical example of incomplete detection and model identification

The numbers in the table represent frequencies of individuals in a hypothetical population of 100 . $R A$ is risk aversion.

\begin{tabular}{|c|c|c|c|}
\hline \multicolumn{4}{|c|}{ Panel A: True state of the world } \\
\hline \multirow{4}{*}{ Manipulator } & & \multicolumn{2}{|c|}{ IQ } \\
\hline & & High & Low \\
\hline & Yes (low RA) & 10 & 10 \\
\hline & No (high RA) & 40 & 40 \\
\hline \multicolumn{4}{|c|}{ Panel B: Non-random detection of manipulators } \\
\hline \multirow{5}{*}{ Manipulator } & & \multicolumn{2}{|c|}{ IQ } \\
\hline & & High & Low \\
\hline & \multirow{2}{*}{ Yes (low RA) - } & 1 & 9 \\
\hline & & 9 & 1 \\
\hline & No (high RA) & 40 & 40 \\
\hline
\end{tabular}




\section{Table II. Definitions of variables}

This table defines the variables used in the models of manipulation and detection. The third column reports the transformation that is applied to the raw data to normalize and scale the variables. Where required by the transformation negative values are multiplied by negative one before and after applying the transformation.

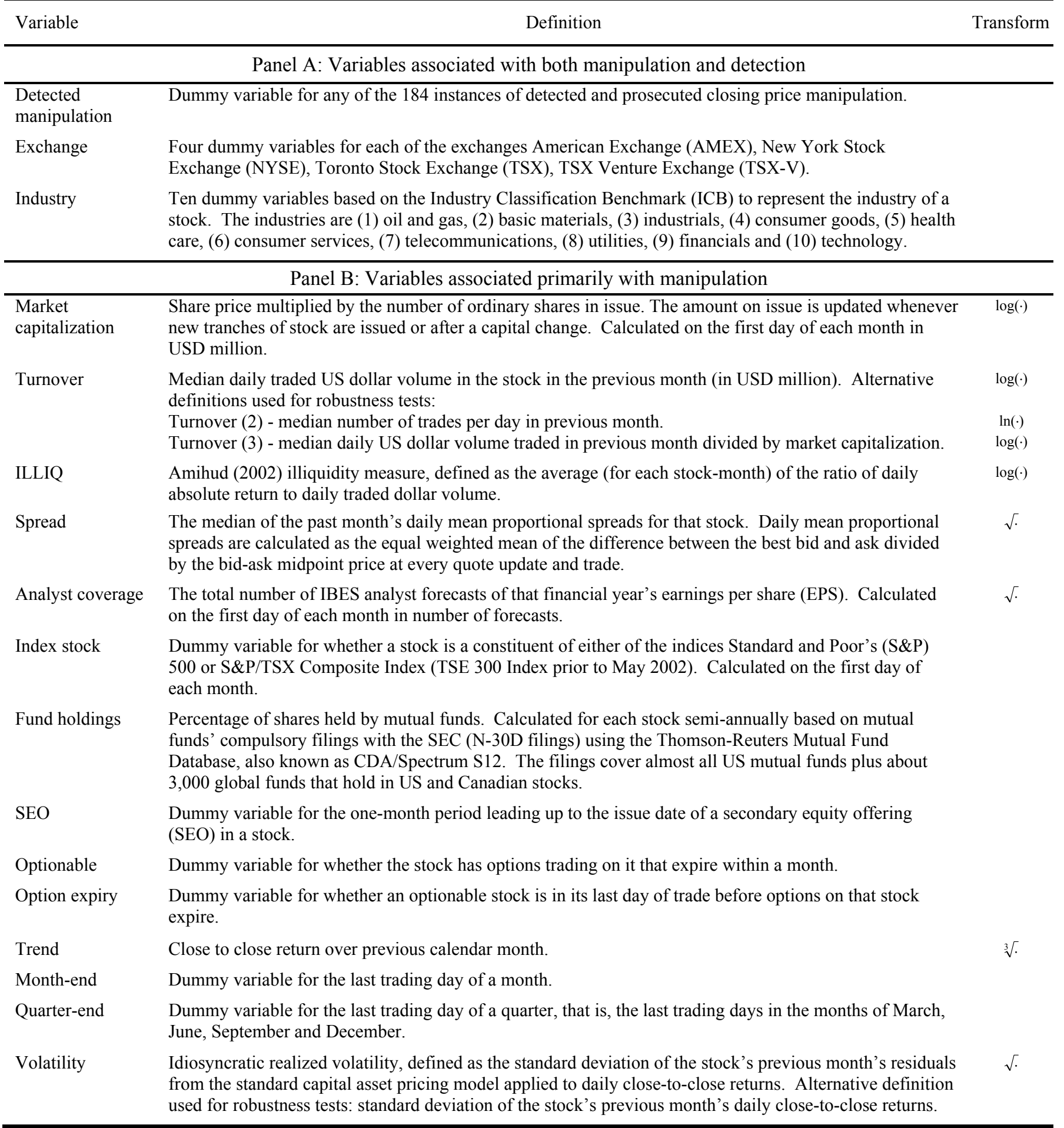




\begin{tabular}{|c|c|c|}
\hline Variable & Definition & Transform \\
\hline \multicolumn{3}{|c|}{ Panel C: Variables associated primarily with detection } \\
\hline Prosecutions & $\begin{array}{l}\text { Number of closing price manipulation prosecutions filed by the market regulators in that country in the } \\
\text { previous year (rolling one year window) based on the date of filling the statement of allegations. }\end{array}$ & \\
\hline $\begin{array}{l}\text { Regulatory } \\
\text { budget }\end{array}$ & $\begin{array}{l}\text { Budget of the principal government regulator divided by the number of common stocks for which the } \\
\text { regulator is responsible. The principal regulator for AMEX and NYSE is the US Securities and Exchange } \\
\text { Commission (SEC) and for TSX and TSX-V it is the Ontario Securities Commission (OSC). Budgets are } \\
\text { taken from the annual reports of the regulators for each regulator's financial year, deflated by the OECD } \\
\text { published CPI of the corresponding country and converted to US dollars. The units of this variable are } \\
\text { '00,000s of US dollars in real (August 1998) terms per common stock. }\end{array}$ & \\
\hline $\begin{array}{l}\text { Abnormal return } \\
(\mathrm{AR})\end{array}$ & $\begin{array}{l}\text { Abnormal day-end return calculated as return from bid-ask midpoint } 30 \text { minutes before close to closing } \\
\text { price (or in the absence of any trades in the last } 30 \text { minutes then midpoint at time of last trade to closing } \\
\text { price) less that stock's previous month's median value. Alternative definitions used for robustness tests: } \\
\text { AR2a, AR2b, AR2c - as per AR } 1 \text { but using last } 60,10 \text { and } 5 \text { minutes of trading in place of } 30 \text { minutes. } \\
\text { AR3 - abnormal daily return calculated as close to close return less that stock's previous month's median } \\
\text { value. }\end{array}$ & $\begin{array}{l}\sqrt{\cdot} \\
\sqrt{\cdot}\end{array}$ \\
\hline Reversion (RV) & $\begin{array}{l}\text { Overnight price reversion calculated as return from closing price to next morning's } 11 \text { am bid-ask midpoint } \\
\text { price. }\end{array}$ & $\sqrt{\cdot}$ \\
\hline $\begin{array}{l}\text { Order imbalance } \\
\text { (OIB) }\end{array}$ & $\begin{array}{l}\text { Day-end order imbalance, defined as the dollar volume of buyer-initiated trades less the dollar volume of } \\
\text { seller-initiated trades during the last } 30 \text { minutes before close, divided by the total dollar volume that day } \\
\text { (to allow comparison across different sized stocks). Has range }[0,1] . \\
\text { Alternative definitions used for robustness tests: } \\
\text { OIB2 - as per OIB but using number of trades in place of dollar volume. } \\
\text { OIB3 - as per OIB but using share volume in place of dollar volume. } \\
\text { OIB4a, OIB4b - as per OIB but using last } 10 \text { and } 5 \text { minutes of trading in place of } 30 \text { minutes. }\end{array}$ & \\
\hline AR time-series & $\begin{array}{l}\text { Abnormal day-end return aggregated over a period of time for a particular stock. Calculated as median } \\
\text { value of AR for that stock in a two-week period starting seven days back in time and ending seven days } \\
\text { forward in time. Alternative definitions used for robustness tests: } \\
\text { AR2 time-series - as per AR time-series but using AR2 in place of AR. } \\
\text { AR3 time-series - as per AR time-series but using AR3 in place of AR. }\end{array}$ & $\begin{array}{l}\sqrt{\cdot} \\
\sqrt{\cdot}\end{array}$ \\
\hline RV time-series & $\begin{array}{l}\text { Reversion aggregated over a period of time for a particular stock. Calculated as median value of RV for } \\
\text { that stock in a two-week period starting seven days back in time and ending seven days forward in time. }\end{array}$ & $\sqrt{\cdot}$ \\
\hline OIB time-series & $\begin{array}{l}\text { Day-end order imbalance aggregated over a period of time for a particular stock. Calculated as median } \\
\text { value of OIB for that stock in a two-week period starting seven days back in time and ending seven days } \\
\text { forward in time. Alternative definitions used for robustness tests: } \\
\text { OIB2 time-series - as per OIB time-series but using OIB2 in place of OIB. } \\
\text { OIB3 time-series - as per OIB time-series but using OIB3 in place of OIB. }\end{array}$ & $\begin{array}{l}\sqrt{\cdot} \\
\sqrt{\cdot}\end{array}$ \\
\hline
\end{tabular}




\section{Table III. Specification of models}

This table defines which variables are used in each of the equations for the three models. Model 1 is a three-equation modified detection controlled estimation (DCE) model, Model 2 is a standard two-equation DCE model and Model 3 is a modified three-equation DCE model with expectations simultaneity. $M()$ is the probability of manipulation, $D()$ is the conditional probability of direct detection (conditional probability of detection in the standard two-equation DCE model) and $I()$ is the conditional probability of indirect detection. Variables are defined in Table II. The symbol + indicates a variable is included as a factor in the corresponding probability.

\begin{tabular}{|c|c|c|c|c|c|c|c|c|}
\hline \multirow{2}{*}{ Variable } & \multicolumn{3}{|c|}{ Model 1} & \multicolumn{2}{|c|}{ Model 2} & \multicolumn{3}{|c|}{ Model 3} \\
\hline & $M()$ & $D()$ & $I()$ & $M()$ & $D()$ & $M()$ & $D()$ & $I()$ \\
\hline Exchange & + & + & + & + & + & + & + & + \\
\hline Industry & + & + & + & + & + & + & + & + \\
\hline Market capitalization & + & & & + & & + & & \\
\hline Turnover & + & & & + & & + & & \\
\hline ILLIQ & + & & & + & & + & & \\
\hline Spread & + & & & + & & + & & \\
\hline Volatility & + & & & + & & + & & \\
\hline Analyst following & + & & & + & & + & & \\
\hline Index stock & + & & & + & & + & & \\
\hline Fund holdings & + & & & + & & + & & \\
\hline SEO & + & & & + & & + & & \\
\hline Optionable & + & & & + & & + & & \\
\hline Option expiry & + & & & + & & + & & \\
\hline Trend & + & & & + & & + & & \\
\hline Month-end & + & & & + & & + & & \\
\hline Quarter-end & + & & & + & & + & & \\
\hline Prosecutions & + & + & + & + & + & + & + & + \\
\hline Regulatory budget & + & + & + & + & + & + & + & + \\
\hline Abnormal return (AR) & & + & & & + & & + & \\
\hline Reversion (RV) & & + & & & + & & + & \\
\hline Order imbalance (OIB) & & + & & & + & & + & \\
\hline AR time-series & & & + & & + & & & + \\
\hline RV time-series & & & + & & + & & & + \\
\hline OIB time-series & & & + & & + & & & + \\
\hline $\mathrm{M}()$ & & & & & & & + & + \\
\hline
\end{tabular}


Table IV. Summary statistics

This table reports summary statistics for variables used in the model of manipulation and detection. The variables are defined in Table II. Raw data are actual observed values whereas Normalized and scaled are values after applying normalizing transformations to the variables. Detected manipulation refers to the sample of stock-days in which manipulation has been detected and prosecuted by a regulator (Yes) and the sample of stock-days without detected and prosecuted manipulation (No). Medians and standard deviations (Std dev) are not reported for binary variables. The units of the raw data are in parentheses under the variable names.

\begin{tabular}{|c|c|c|c|c|c|c|c|}
\hline \multirow[b]{2}{*}{ Variable } & \multirow{2}{*}{$\begin{array}{l}\text { Detected } \\
\text { manipulation }\end{array}$} & \multicolumn{3}{|c|}{ Raw data } & \multicolumn{3}{|c|}{ Normalized and scaled } \\
\hline & & Mean & Std dev & Median & Mean & Std dev & Median \\
\hline \multicolumn{8}{|c|}{ Panel A: Variables associated with both manipulation and detection } \\
\hline $\begin{array}{l}\text { Exchange (AMEX) } \\
\text { (Binary) }\end{array}$ & $\begin{array}{l}\text { Yes } \\
\text { No }\end{array}$ & $\begin{array}{l}0.17 \\
0.13\end{array}$ & & & $\begin{array}{l}0.17 \\
0.13\end{array}$ & & \\
\hline $\begin{array}{l}\text { Exchange (TSX) } \\
\text { (Binary) }\end{array}$ & $\begin{array}{l}\text { Yes } \\
\text { No }\end{array}$ & $\begin{array}{l}0.46 \\
0.25\end{array}$ & & & $\begin{array}{l}0.46 \\
0.25\end{array}$ & & \\
\hline $\begin{array}{l}\text { Exchange (TSX-V) } \\
\text { (Binary) }\end{array}$ & $\begin{array}{l}\text { Yes } \\
\text { No }\end{array}$ & $\begin{array}{l}0.20 \\
0.05\end{array}$ & & & $\begin{array}{l}0.20 \\
0.05\end{array}$ & & \\
\hline $\begin{array}{l}\text { Exchange (NYSE) } \\
\text { (Binary) }\end{array}$ & $\begin{array}{l}\text { Yes } \\
\text { No }\end{array}$ & $\begin{array}{l}0.18 \\
0.56\end{array}$ & & & $\begin{array}{l}0.18 \\
0.56\end{array}$ & & \\
\hline \multicolumn{8}{|c|}{ Panel B: Variables associated primarily with manipulation } \\
\hline $\begin{array}{l}\text { Market capitalization } \\
\text { (USD million) }\end{array}$ & $\begin{array}{l}\text { Yes } \\
\text { No }\end{array}$ & $\begin{array}{c}442 \\
2,963\end{array}$ & $\begin{array}{c}1,579 \\
12,737\end{array}$ & $\begin{array}{c}67 \\
236\end{array}$ & $\begin{array}{l}2.01 \\
2.39\end{array}$ & $\begin{array}{l}0.58 \\
1.01\end{array}$ & $\begin{array}{l}1.83 \\
2.37\end{array}$ \\
\hline $\begin{array}{l}\text { Turnover } \\
\text { (USD million) }\end{array}$ & $\begin{array}{l}\text { Yes } \\
\text { No }\end{array}$ & $\begin{array}{l}0.97 \\
8.07\end{array}$ & $\begin{array}{c}4.98 \\
31.29\end{array}$ & $\begin{array}{l}0.08 \\
0.21\end{array}$ & $\begin{array}{l}4.96 \\
5.43\end{array}$ & $\begin{array}{l}0.61 \\
1.29\end{array}$ & $\begin{array}{l}4.89 \\
5.31\end{array}$ \\
\hline $\begin{array}{l}\text { ILLIQ } \\
\quad(\% / \text { USD } 10,000)\end{array}$ & $\begin{array}{l}\text { Yes } \\
\text { No }\end{array}$ & $\begin{array}{l}0.48 \\
0.36\end{array}$ & $\begin{array}{l}0.36 \\
0.43\end{array}$ & $\begin{array}{l}0.47 \\
0.07\end{array}$ & $\begin{array}{l}2.09 \\
1.54\end{array}$ & $\begin{array}{l}1.56 \\
1.87\end{array}$ & $\begin{array}{l}2.02 \\
0.31\end{array}$ \\
\hline $\begin{array}{l}\text { Spread } \\
(\%)\end{array}$ & $\begin{array}{l}\text { Yes } \\
\text { No }\end{array}$ & $\begin{array}{l}2.71 \\
2.32\end{array}$ & $\begin{array}{l}1.44 \\
3.68\end{array}$ & $\begin{array}{l}2.56 \\
0.88\end{array}$ & $\begin{array}{l}1.57 \\
1.22\end{array}$ & $\begin{array}{l}0.49 \\
0.91\end{array}$ & $\begin{array}{l}1.60 \\
0.94\end{array}$ \\
\hline $\begin{array}{l}\text { Analyst coverage } \\
\text { (Count) }\end{array}$ & $\begin{array}{l}\text { Yes } \\
\text { No }\end{array}$ & $\begin{array}{l}1.63 \\
3.93\end{array}$ & $\begin{array}{l}4.42 \\
5.94\end{array}$ & $\begin{array}{l}0.00 \\
1.00\end{array}$ & $\begin{array}{l}0.62 \\
1.32\end{array}$ & $\begin{array}{l}1.12 \\
1.48\end{array}$ & $\begin{array}{l}0.00 \\
1.00\end{array}$ \\
\hline $\begin{array}{l}\text { Fund holdings } \\
(\%)\end{array}$ & $\begin{array}{l}\text { Yes } \\
\text { No }\end{array}$ & $\begin{array}{c}5.45 \\
11.98\end{array}$ & $\begin{array}{l}8.50 \\
13.2\end{array}$ & $\begin{array}{l}1.12 \\
6.98\end{array}$ & $\begin{array}{c}5.45 \\
11.98\end{array}$ & $\begin{array}{l}8.50 \\
13.2\end{array}$ & $\begin{array}{l}1.12 \\
6.98\end{array}$ \\
\hline $\begin{array}{c}\text { Trend } \\
(\%)\end{array}$ & $\begin{array}{l}\text { Yes } \\
\text { No }\end{array}$ & $\begin{array}{c}2.81 \\
-0.14\end{array}$ & $\begin{array}{l}22.1 \\
17.5\end{array}$ & $\begin{array}{l}1.59 \\
0.00\end{array}$ & $\begin{array}{l}0.21 \\
0.01\end{array}$ & $\begin{array}{l}2.35 \\
2.06\end{array}$ & $\begin{array}{l}1.17 \\
0.00\end{array}$ \\
\hline $\begin{array}{l}\text { Volatility } \\
(\%)\end{array}$ & $\begin{array}{l}\text { Yes } \\
\text { No }\end{array}$ & $\begin{array}{l}1.87 \\
3.39\end{array}$ & $\begin{array}{l}1.90 \\
3.80\end{array}$ & $\begin{array}{l}1.48 \\
2.18\end{array}$ & $\begin{array}{l}1.10 \\
1.67\end{array}$ & $\begin{array}{l}0.82 \\
0.78\end{array}$ & $\begin{array}{l}1.21 \\
1.48\end{array}$ \\
\hline $\begin{array}{l}\text { Index stock } \\
\text { (Binary) }\end{array}$ & $\begin{array}{l}\text { Yes } \\
\text { No }\end{array}$ & $\begin{array}{l}0.11 \\
0.18\end{array}$ & & & $\begin{array}{l}0.11 \\
0.18\end{array}$ & & \\
\hline $\begin{array}{l}\text { SEO } \\
\text { (Binary) }\end{array}$ & $\begin{array}{l}\text { Yes } \\
\text { No }\end{array}$ & $\begin{array}{l}0.013 \\
0.006\end{array}$ & & & $\begin{array}{l}0.013 \\
0.006\end{array}$ & & \\
\hline $\begin{array}{l}\text { Optionable } \\
\text { (Binary) }\end{array}$ & $\begin{array}{l}\text { Yes } \\
\text { No }\end{array}$ & $\begin{array}{l}0.09 \\
0.28\end{array}$ & & & $\begin{array}{l}0.09 \\
0.28\end{array}$ & & \\
\hline $\begin{array}{l}\text { Option expiry } \\
\text { (Binary) }\end{array}$ & $\begin{array}{l}\text { Yes } \\
\text { No }\end{array}$ & $\begin{array}{l}0.00 \\
0.01\end{array}$ & & & $\begin{array}{l}0.00 \\
0.01\end{array}$ & & \\
\hline $\begin{array}{l}\text { Month-end } \\
\text { (Binary) }\end{array}$ & $\begin{array}{l}\text { Yes } \\
\text { No }\end{array}$ & $\begin{array}{l}0.31 \\
0.05\end{array}$ & & & $\begin{array}{l}0.31 \\
0.05\end{array}$ & & \\
\hline $\begin{array}{l}\text { Quarter-end } \\
\text { (Binary) }\end{array}$ & $\begin{array}{l}\text { Yes } \\
\text { No }\end{array}$ & $\begin{array}{l}0.20 \\
0.02\end{array}$ & & & $\begin{array}{l}0.20 \\
0.02\end{array}$ & & \\
\hline
\end{tabular}


Table IV (continued)

\begin{tabular}{|c|c|c|c|c|c|c|c|}
\hline \multirow[b]{2}{*}{ Variable } & \multirow{2}{*}{$\begin{array}{c}\text { Detected } \\
\text { manipulation }\end{array}$} & \multicolumn{3}{|c|}{ Raw data } & \multicolumn{3}{|c|}{ Normalized and scaled } \\
\hline & & Mean & Std dev & Median & Mean & Std dev & Median \\
\hline \multicolumn{8}{|c|}{ Panel C: Variables associated primarily with detection } \\
\hline $\begin{array}{l}\text { Prosecutions } \\
\text { (Count) }\end{array}$ & $\begin{array}{l}\text { Yes } \\
\text { No }\end{array}$ & $\begin{array}{l}0.47 \\
0.73\end{array}$ & $\begin{array}{l}0.66 \\
0.99\end{array}$ & $\begin{array}{l}0.00 \\
0.00\end{array}$ & $\begin{array}{l}0.47 \\
0.73\end{array}$ & $\begin{array}{l}0.66 \\
0.99\end{array}$ & $\begin{array}{l}0.00 \\
0.00\end{array}$ \\
\hline $\begin{array}{l}\text { Regulatory budget } \\
\text { (USD100,000/stock) }\end{array}$ & $\begin{array}{l}\text { Yes } \\
\text { No }\end{array}$ & $\begin{array}{c}58.1 \\
130\end{array}$ & $\begin{array}{l}75.5 \\
90.9\end{array}$ & $\begin{array}{l}9.80 \\
165\end{array}$ & $\begin{array}{l}0.58 \\
1.30\end{array}$ & $\begin{array}{l}0.76 \\
0.91\end{array}$ & $\begin{array}{l}0.10 \\
1.65\end{array}$ \\
\hline $\begin{array}{l}\text { Abnormal return (AR) } \\
(\%)\end{array}$ & $\begin{array}{l}\text { Yes } \\
\text { No }\end{array}$ & $\begin{array}{l}1.24 \\
0.04\end{array}$ & $\begin{array}{l}2.39 \\
2.54\end{array}$ & $\begin{array}{l}0.86 \\
0.00\end{array}$ & $\begin{array}{l}0.72 \\
0.01\end{array}$ & $\begin{array}{l}1.17 \\
1.06\end{array}$ & $\begin{array}{l}0.93 \\
0.00\end{array}$ \\
\hline $\begin{array}{l}\text { Reversion (RV) } \\
(\%)\end{array}$ & $\begin{array}{l}\text { Yes } \\
\text { No }\end{array}$ & $\begin{array}{r}1.55 \\
-0.19\end{array}$ & $\begin{array}{l}3.72 \\
3.66\end{array}$ & $\begin{array}{l}1.71 \\
0.00\end{array}$ & $\begin{array}{c}0.93 \\
-0.05\end{array}$ & $\begin{array}{l}1.40 \\
1.39\end{array}$ & $\begin{array}{l}1.31 \\
0.00\end{array}$ \\
\hline $\begin{array}{r}\text { Order imbalance (OIB) } \\
\text { (Dimensionless ratio) }\end{array}$ & $\begin{array}{l}\text { Yes } \\
\text { No }\end{array}$ & $\begin{array}{l}0.11 \\
0.00\end{array}$ & $\begin{array}{l}0.25 \\
0.09\end{array}$ & $\begin{array}{l}0.02 \\
0.00\end{array}$ & $\begin{array}{l}0.11 \\
0.00\end{array}$ & $\begin{array}{l}0.25 \\
0.09\end{array}$ & $\begin{array}{l}0.02 \\
0.00\end{array}$ \\
\hline $\begin{array}{l}\text { AR time series } \\
(\%)\end{array}$ & $\begin{array}{l}\text { Yes } \\
\text { No }\end{array}$ & $\begin{array}{l}0.20 \\
0.01\end{array}$ & $\begin{array}{l}0.77 \\
1.17\end{array}$ & $\begin{array}{l}0.14 \\
0.00\end{array}$ & $\begin{array}{l}0.20 \\
0.00\end{array}$ & $\begin{array}{l}0.72 \\
0.67\end{array}$ & $\begin{array}{l}0.37 \\
0.00\end{array}$ \\
\hline $\begin{array}{l}\text { RV time series } \\
\quad(\%)\end{array}$ & $\begin{array}{l}\text { Yes } \\
\text { No }\end{array}$ & $\begin{array}{c}1.15 \\
-0.17\end{array}$ & $\begin{array}{l}1.28 \\
1.78\end{array}$ & $\begin{array}{l}1.12 \\
0.00\end{array}$ & $\begin{array}{c}0.81 \\
-0.06\end{array}$ & $\begin{array}{l}0.85 \\
0.91\end{array}$ & $\begin{array}{l}1.06 \\
0.00\end{array}$ \\
\hline $\begin{array}{l}\text { OIB time series } \\
\text { (Dimensionless ratio) }\end{array}$ & $\begin{array}{l}\text { Yes } \\
\text { No }\end{array}$ & $\begin{array}{l}0.01 \\
0.00\end{array}$ & $\begin{array}{l}0.04 \\
0.01\end{array}$ & $\begin{array}{l}0.00 \\
0.00\end{array}$ & $\begin{array}{l}0.15 \\
0.04\end{array}$ & $\begin{array}{l}0.45 \\
0.15\end{array}$ & $\begin{array}{l}0.00 \\
0.00\end{array}$ \\
\hline Observations & $\begin{array}{l}\text { Yes } \\
\text { No }\end{array}$ & & & & & & \\
\hline
\end{tabular}




\section{Table V. Model estimation}

This table reports the results of the estimation of the models. Model 1 is a three-equation modified DCE model, Model 2 is a standard two-equation DCE model and Model 3 is a modified three-equation DCE model with expectations simultaneity. $M()$ is the probability of manipulation, $D($ ) is the conditional probability of direct detection (detection in the standard two-equation DCE model) and $I()$ is the conditional probability of indirect detection. Variables are defined in Table II. Numbers not in brackets are the coefficient estimates. Numbers in brackets are the marginal effects (partial derivatives of the corresponding probability with respect to each of the variables, reported as a percentage of the estimated corresponding probability). Pseudo R-squared is McFadden's likelihood ratio index (one minus the ratio of the log-likelihood with all predictors and the log-likelihood with intercepts only). Significance at the $10 \%, 5 \%$ and $1 \%$ levels is indicated by $*, * *$ and $* * *$ respectively.

\begin{tabular}{|c|c|c|c|c|c|c|c|c|}
\hline \multirow[b]{2}{*}{ Variable } & \multicolumn{3}{|c|}{ Model 1} & \multicolumn{2}{|c|}{ Model 2} & \multicolumn{3}{|c|}{ Model 3} \\
\hline & $M()$ & $D()$ & $I()$ & $M()$ & $D()$ & $M()$ & $D()$ & $I()$ \\
\hline Regulatory budget & $\begin{array}{c}-2.01 * * * \\
(-1.98)\end{array}$ & $\begin{array}{c}1.69 * * * \\
(1.63)\end{array}$ & $\begin{array}{l}6.48 * * \\
(6.14)\end{array}$ & $\begin{array}{c}-2.11 * * * \\
(-2.09)\end{array}$ & $\begin{array}{c}1.59 * * * \\
(1.52)\end{array}$ & $\begin{array}{c}-2.01 * * * \\
(-1.99)\end{array}$ & $\begin{array}{l}1.68 * * \\
(1.62)\end{array}$ & $\begin{array}{l}6.49^{* *} \\
(6.14)\end{array}$ \\
\hline Analyst coverage & $\begin{array}{c}-0.37 * * * \\
(-0.36)\end{array}$ & & & $\begin{array}{c}-0.42 * * * \\
(-0.42)\end{array}$ & & $\begin{array}{c}-0.38 * * * \\
(-0.38)\end{array}$ & & \\
\hline Index stock & $\begin{array}{c}-1.22 * * * \\
(-1.21)\end{array}$ & & & $\begin{array}{c}-1.29 * * * \\
(-1.28)\end{array}$ & & $\begin{array}{c}-1.22 * * * \\
(-1.21)\end{array}$ & & \\
\hline Fund holdings & $\begin{array}{c}-0.08 * * * \\
(-0.08)\end{array}$ & & & $\begin{array}{c}-0.09 * * * \\
(-0.09)\end{array}$ & & $\begin{array}{c}-0.08 * * * \\
(-0.08)\end{array}$ & & \\
\hline Market capitalization & $\begin{array}{c}0.73 * * * \\
(0.72)\end{array}$ & & & $\begin{array}{c}0.71 * * * \\
(0.71)\end{array}$ & & $\begin{array}{c}0.73^{* * *} \\
(0.72)\end{array}$ & & \\
\hline ILLIQ & $\begin{array}{c}-0.43 * * * \\
(-0.43)\end{array}$ & & & $\begin{array}{c}-0.37 * * * \\
(-0.37)\end{array}$ & & $\begin{array}{c}-0.44 * * * \\
(-0.44)\end{array}$ & & \\
\hline Month-end (ME) & $\begin{array}{c}1.02 * * * \\
(1.01)\end{array}$ & & & $\begin{array}{c}0.71 * * \\
(0.70)\end{array}$ & & $\begin{array}{c}1.01 * * * \\
(0.99)\end{array}$ & & \\
\hline Quarter-end (QE) & $\begin{array}{c}1.09 * * * \\
(1.07)\end{array}$ & & & $\begin{array}{c}0.70 \\
(0.69)\end{array}$ & & $\begin{array}{c}1.07 * * * \\
(1.06)\end{array}$ & & \\
\hline ME * Fund holdings & $\begin{array}{c}0.06^{* * *} \\
(0.06)\end{array}$ & & & $\begin{array}{c}0.08^{* * *} \\
(0.08)\end{array}$ & & $\begin{array}{c}0.06^{* * * *} \\
(0.06)\end{array}$ & & \\
\hline QE * Fund holdings & $\begin{array}{l}0.04^{*} \\
(0.04)\end{array}$ & & & $\begin{array}{l}0.05^{*} \\
(0.05)\end{array}$ & & $\begin{array}{l}0.04 * \\
(0.04)\end{array}$ & & \\
\hline Volatility & $\begin{array}{c}-0.98 * * * \\
(-0.97)\end{array}$ & & & $\begin{array}{c}-0.69 * * * \\
(-0.69)\end{array}$ & & $\begin{array}{c}-0.93 * * * \\
(-0.92)\end{array}$ & & \\
\hline Abnormal return (AR) & & $\begin{array}{c}0.85^{* * *} \\
(0.82)\end{array}$ & & & $\begin{array}{c}0.71 * * * \\
(0.68)\end{array}$ & & $\begin{array}{c}0.84 * * * \\
(0.81)\end{array}$ & \\
\hline Reversion (RV) & & $\begin{array}{c}0.30 * * * \\
(0.29)\end{array}$ & & & $\begin{array}{c}0.27 * * * \\
(0.25)\end{array}$ & & $\begin{array}{c}0.29 * * * \\
(0.28)\end{array}$ & \\
\hline Order imbalance (OIB) & & $\begin{array}{l}1.43 * * \\
(1.37)\end{array}$ & & & $\begin{array}{c}1.10 \\
(1.05)\end{array}$ & & $\begin{array}{l}1.41 * * \\
(1.36)\end{array}$ & \\
\hline AR time series & & & $\begin{array}{c}3.17 * * * \\
(3.00)\end{array}$ & & $\begin{array}{c}0.25 \\
(0.24)\end{array}$ & & & $\begin{array}{c}3.18^{* * *} \\
(3.01)\end{array}$ \\
\hline RV time series & & & $\begin{array}{c}7.64 * * * \\
(7.23)\end{array}$ & & $\begin{array}{c}1.10^{* * *} \\
(1.05)\end{array}$ & & & $\begin{array}{c}7.66^{* * * *} \\
(7.24)\end{array}$ \\
\hline OIB time series & & & $\begin{array}{c}3.12 \\
(2.95)\end{array}$ & & $\begin{array}{c}0.03 \\
(0.03)\end{array}$ & & & $\begin{array}{c}3.12 \\
(2.95)\end{array}$ \\
\hline $\mathrm{M}(\mathbf{)}$ & & & & & & & $0.14 * * *$ & 0.01 \\
\hline Exchange dummies & Yes & Yes & Yes & Yes & Yes & Yes & Yes & Yes \\
\hline Observations & & $1,249,932$ & & 1,2 & 932 & & $1,249,93$ & \\
\hline Pseudo R-squared & & 0.23 & & & & & 0.23 & \\
\hline
\end{tabular}


Table VI. Bootstrap-based corrections for double-clustered errors and finite-sample bias

This table reports the results of Model 1 (the three-equation modified DCE model from Table V) estimated using a reduced random sample and bootstraps of 500 replications each. Double-clustered errors uses a bootstrap algorithm that provides consistent standard error estimates when errors cluster by stock and by date. Bias-corrected estimates uses a bootstrap algorithm that corrects parameter estimates for nonlinear estimator finite-sample bias. $M()$ is the probability of manipulation, $D()$ is the conditional probability of direct detection and $I()$ is the conditional probability of indirect detection. Variables are defined in Table II. Numbers not in brackets are the coefficient estimates. Numbers in brackets are the marginal effects (partial derivatives of the corresponding probability with respect to each of the variables, reported as a percentage of the estimated corresponding probability). Significance at the $10 \%, 5 \%$ and $1 \%$ levels is indicated by $*, * *$ and $* * *$ respectively.

\begin{tabular}{|c|c|c|c|c|c|c|}
\hline \multirow[b]{2}{*}{ Variable } & \multicolumn{3}{|c|}{ Double-clustered errors } & \multicolumn{3}{|c|}{ Bias-corrected estimates } \\
\hline & $M()$ & $D()$ & $I()$ & $M()$ & $D()$ & $I()$ \\
\hline Regulatory budget & $\begin{array}{c}-2.06 * * * \\
(-2.04)\end{array}$ & $\begin{array}{c}1.77 * * * \\
(1.69)\end{array}$ & $\begin{array}{c}6.51 * * * \\
(6.18)\end{array}$ & $\begin{array}{c}-1.87 * * * \\
(-1.86)\end{array}$ & $\begin{array}{c}1.69 * * * \\
(1.60)\end{array}$ & $\begin{array}{c}6.68 * * * \\
(5.95)\end{array}$ \\
\hline Analyst following & $\begin{array}{l}-0.12^{*} \\
(-0.12)\end{array}$ & & & $\begin{array}{l}-0.16^{*} \\
(-0.16)\end{array}$ & & \\
\hline Index stock & $\begin{array}{c}-1.22 * * * \\
(-1.21)\end{array}$ & & & $\begin{array}{c}-1.24 * * * \\
(-1.23)\end{array}$ & & \\
\hline Fund holdings & $\begin{array}{c}-0.07 * * * \\
(-0.07)\end{array}$ & & & $\begin{array}{c}-0.07 * * * \\
(-0.07)\end{array}$ & & \\
\hline Market capitalization & $\begin{array}{c}0.83 * * * \\
(0.82)\end{array}$ & & & $\begin{array}{c}0.77 * * * \\
(0.76)\end{array}$ & & \\
\hline ILLIQ & $\begin{array}{c}-0.12 \\
(-0.12)\end{array}$ & & & $\begin{array}{c}-0.14 \\
(-0.14)\end{array}$ & & \\
\hline Month-end (ME) & $\begin{array}{c}1.56^{* * *} \\
(1.54)\end{array}$ & & & $\begin{array}{c}1.41 * * * \\
(1.40)\end{array}$ & & \\
\hline Quarter-end (QE) & $\begin{array}{c}1.70 * * * \\
(1.69)\end{array}$ & & & $\begin{array}{c}1.44 * * * \\
(1.43)\end{array}$ & & \\
\hline ME * Fund holdings & $\begin{array}{c}0.03 * * * \\
(0.03)\end{array}$ & & & $\begin{array}{c}0.04 * * * \\
(0.04)\end{array}$ & & \\
\hline QE * Fund holdings & $\begin{array}{c}0.01 \\
(0.01)\end{array}$ & & & $\begin{array}{c}0.01 \\
(0.01)\end{array}$ & & \\
\hline Volatility & $\begin{array}{c}-2.37 * * * \\
(-2.35)\end{array}$ & & & $\begin{array}{c}-2.05 * * * \\
(-2.04)\end{array}$ & & \\
\hline Abnormal return (AR) & & $\begin{array}{c}1.22 * * * \\
(1.17)\end{array}$ & & & $\begin{array}{c}1.21 * * * \\
(1.15)\end{array}$ & \\
\hline Reversion (RV) & & $\begin{array}{c}0.45 * * * \\
(0.43)\end{array}$ & & & $\begin{array}{c}0.45^{* * *} \\
(0.42)\end{array}$ & \\
\hline Order imbalance (OIB) & & $\begin{array}{c}1.86^{* * *} \\
(1.78)\end{array}$ & & & $\begin{array}{c}2.38 * * * \\
(1.24)\end{array}$ & \\
\hline AR time series & & & $\begin{array}{c}3.01 * * \\
(2.86)\end{array}$ & & & $\begin{array}{c}2.14 * * * \\
(3.67)\end{array}$ \\
\hline RV time series & & & $\begin{array}{c}7.79 * * * \\
(7.40)\end{array}$ & & & $\begin{array}{c}7.47 * * * \\
(7.62)\end{array}$ \\
\hline OIB time series & & & $\begin{array}{c}3.26 * * * \\
(3.10)\end{array}$ & & & $\begin{array}{c}3.27 * * * \\
(3.06)\end{array}$ \\
\hline Exchange dummies & Yes & Yes & Yes & Yes & Yes & Yes \\
\hline Observations & & 12,681 & & & 12,681 & \\
\hline
\end{tabular}




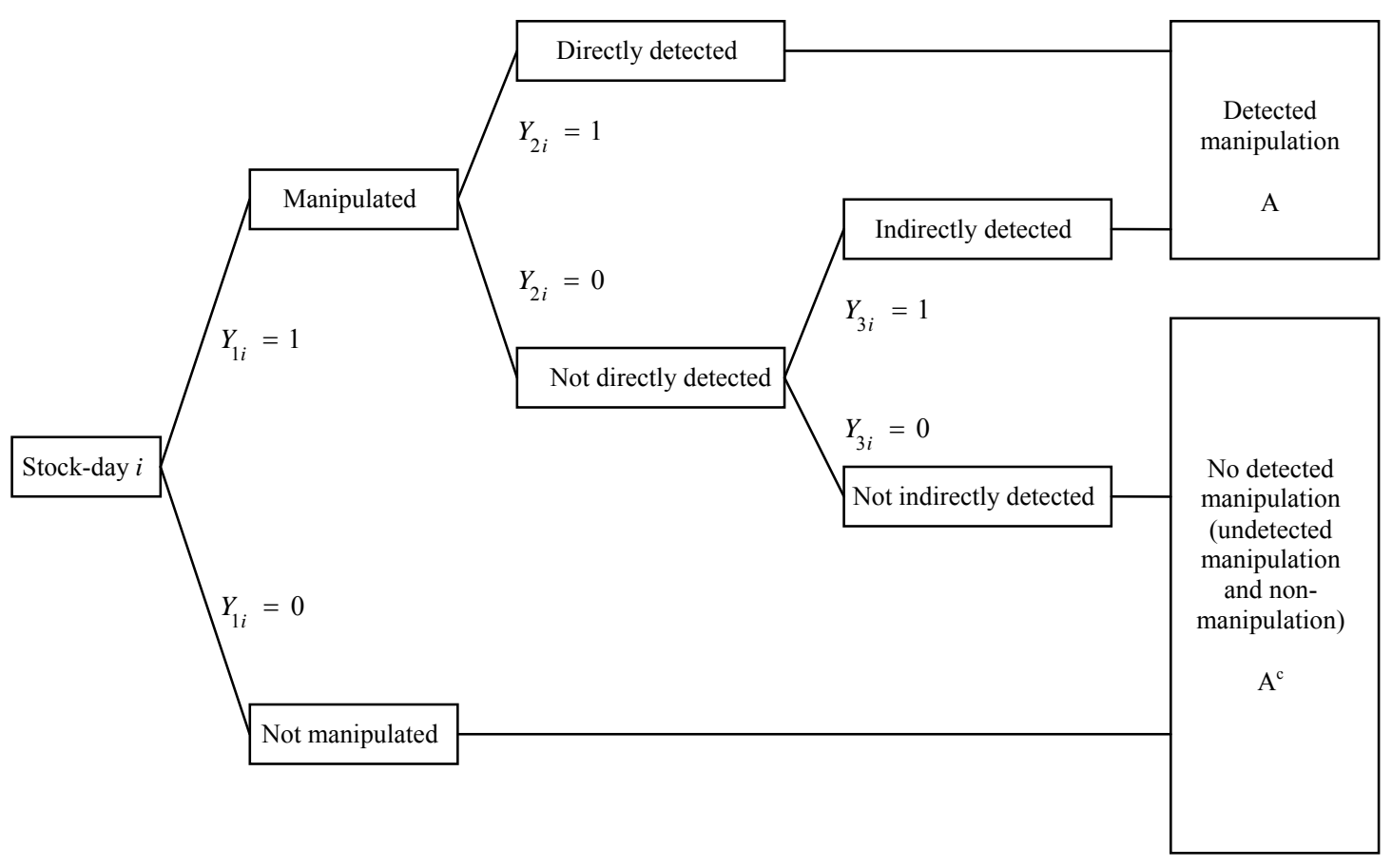

Figure 1. Modified detection controlled estimation model. 